\title{
Modelo de Ising ferromagnético com campo externo periódico
}

\author{
Manuel Alejandro González Navarrete
}

\author{
TESE APRESENTADA \\ $\mathrm{AO}$ \\ Instituto de Matemática e EstatísticA \\ DA \\ Universidade DE SÃo PAUlo \\ PARA \\ OBTENÇÃO DO TÍTULO \\ $\mathrm{DE}$ \\ DOUTOR EM CIÊNCIAS
}

\author{
Programa: Estatística \\ Orientador: Prof. Dr. Anatoly Yambartsev \\ Coorientador: Prof. Dr. Eugene Pechersky
}

Durante o desenvolvimento deste trabalho o autor recebeu auxílio financeiro do BecasChile

São Paulo, junho de 2015 


\section{Modelo de Ising ferromagnético com campo externo periódico}

Esta versão da tese contém as correções e alterações sugeridas pela Comissão Julgadora durante a defesa realizada em 07/05/2015. Uma cópia da versão original está disponível no Instituto de Matemática e Estatística da Universidade de São Paulo.

Comissão Julgadora:

- Prof. Dr. Anatoly Yambartsev (Presidente) - IME-USP

- Prof. Dr. Luiz Renato Gonçalves Fontes - IME-USP

- Prof. Dr. Rodrigo Bissacot Proença - IME-USP

- Profa. Dra. Maria Eulalia Vares - IM-UFRJ

- Prof. Dr. Domingos Humberto Urbano Marchetti - IF-USP 


\section{Agradecimentos}

Primeiramente, agradeço ao meu orientador Anatoly Yambartsev pelos ensinamentos, a paciência e o respeito para trabalhar juntos nesse curto período de tese. Gostaria também de agradecer ao professor Eugene Pechersky pela paixão com que ele faz matemática. Realmente, foi um orgulho e uma grande alegria trabalhar com eles.

Agradeço também aos professores, Stefan Zohren e Rodrigo Bissacot, das poucas conversas que tive com eles aprendi muito, e sem dúvida foram importantes na elaboração dessa tese.

Agradeço à minha família, embora a distância, sempre estiveram comigo. Com muito amor para minha sobrinha mais nova, a Josefina e o meu sobrinho-neto Ignacio.

Aos meus amigos do IME, especialmente agradeço ao Tiago Maia, o Leandroza e o Wagner, valeu pelo futebol. Também, e de forma muito especial, agradeço ao Javier Cerda por todas as nossas conversas e suas orientações. Aos amigos do NUMEC: Alejandro, Alejandra, Aline, Andrea, Douglas, Estefano, Gabriel, Guilherme, Karina, e muito especialmente ao Rodrigo, valeu mesmo pelas correções e as conversas.

Aos meus amigos chilenos que tive o prazer de conhecer aqui em São Paulo. Especialmente à Mónica e o Alvaro, com certeza eles representam toda essa galera.

Também, aos amigos que estão no Chile e sempre me apoiaram e me mostraram o seu carinho constantemente. Especialmente ao meu amigo Eduardo Infante. Aos grandes amigos de Loncoche: Alvaro, Jona, Robinson, Rodolfo e o Rodrigo.

Finalmente e com muito amor agradeço à Natalia, gracias por todo flaca. 


\section{Resumo}

GONZÁLEZ NAVARRETE, M. A. Modelo de Ising ferromagnético com campo externo periódico. 54 f. Tese (Doutorado) - Instituto de Matemática e Estatística, Universidade de São Paulo, São Paulo, 2015.

Estudamos o diagrama de fases para uma classe de modelos de Ising ferromagnéticos em $\mathbb{Z}^{2}$, com campo magnético externo periódico. O campo externo assume dois valores: $h \mathrm{e}-h$, onde $h>0$. Os sítios associados a valores positivos e negativos do campo externo, formam uma configuração em forma de tabuleiro de xadrez (nós chamamos de cell-board configuration), com células retangulares de tamanho $L_{1} \times L_{2}$ sítios, de tal forma que o valor total do campo externo é zero. Como principal resultado, mostramos a presença de uma transição de fase de primeira ordem. A transição de fase existe para $h<\frac{2 J}{L_{1}}+\frac{2 J}{L_{2}}$, onde $J$ é uma constante de interação. A prova é construida usando o método de reflection positivity $(R P)$. Aplicamos uma desigualdade que é normalmente referida como a estimativa de chessboard. Além disso, incluímos uma região de unicidade da medida de Gibbs em $h>4 J$, isto usando um critério baseado nas ideias de percolação em desacordo.

Palavras chave: modelo de Ising, campo externo periódico, condição de Peierls, positividade por reflexão, transição de fase, percolação em desacordo. 


\section{Abstract}

GONZÁLEZ NAVARRETE, M. A. Ferromagnetic Ising model with periodical external fields. 54 p. Thesis (PhD) - Instituto de Matemática e Estatística, Universidade de São Paulo, São Paulo, 2015.

We study the low-temperature phase diagram for a ferromagnetic Ising model on $\mathbb{Z}^{2}$, with a periodical external magnetic field. The external field takes two values: $h$ and $-h$, where $h>0$. The sites associated with positive and negative values of external field form a cell-board configuration with rectangular cells of sides $L_{1} \times L_{2}$ sites, such that the total value of the external field is zero. As a main result, we show the presence of a first-order phase transition. The phase transition holds if $h<\frac{2 J}{L_{1}}+\frac{2 J}{L_{2}}$, where $J$ is an interaction constant. We use the reflection positivity (RP) method. We apply a key inequality which is usually referred to as the chessboard estimate. Furthermore, we prove uniqueness for Gibbs measure in $h>4 J$, using a uniqueness condition obtained in terms of disagreement percolation.

Keywords: Ising model, periodical external field, Peierls condition, reflection positivity, phase transition, disagreement percolation. 


\section{Sumário}

$\begin{array}{lc}\text { Lista de Figuras } & \text { ix }\end{array}$

1 Introdução $\quad 1$

1.1 Objetivos da tese . . . . . . . . . . . . . . . . . . . . 3

1.2 Organização do texto . . . . . . . . . . . . . . . . . . 3

2 Definição do Modelo e Enunciado do Problema 5

2.1 Modelo de Ising ferromagnético com campo externo do tipo cell-board . . . . . . . 5

2.1.1 O modelo de Ising antiferromagnético com campo externo uniforme . . . . . . 9

2.1.2 Ising ferromagnético com campo externo alternado de Nardi et al. [37] . . . . 9

2.2 Estudo do diagrama de fases a baixas temperaturas . . . . . . . . . . . . . . . 10

3 Técnicas Aplicadas $\quad 13$

3.1 A propriedade de Reflection Positivity $(\mathrm{RP}) \ldots \ldots \ldots$. . . . . . . . . . . 13

3.1.1 Estimativa de chessboard e transição de fase . . . . . . . . . . . . . . . . . . . 14

3.2 O método de Disagreement Percolation . . . . . . . . . . . . . . . . . . . . . . . . . 22

3.2 .1 Critério de unicidade . . . . . . . . . . . . . . . . . . . 24

4 Resultados Principais $\quad 25$

4.1 Unicidade da medida de Gibbs . . . . . . . . . . . . . . . . . . . . . 25

4.1 .1 Teorema de unicidade para $h>4 J \ldots \ldots \ldots \ldots \ldots$

4.2 Transição de fase . . . . . . . . . . . . . . . . . . . . . . . 26

4.2.1 Teorema de transição de fase para $h<2 J / L_{1}+2 J / L_{2} \ldots \ldots \ldots$. . . . . 26

4.2.2 Corolário para o Ising antiferromagnético com campo externo uniforme . . . . 27

4.2.3 Transição de fase para um campo externo de faixas alternadas . . . . . . . . . 28

5 Demonstrações $\quad 31$

5.1 Prova do Teorema de unicidade . . . . . . . . . . . . . . . . . . 31

5.2 Prova da transição de fase no modelo de Ising do tipo cell-board . . . . . . . . . . . 33

5.2 .1 Provas dos resultados auxiliares . . . . . . . . . . . . . . . . 37

5.3 Prova da transição de fase no modelo de Ising com faixas alternadas . . . . . . . . . 47

Referências Bibliográficas $\quad 51$ 


\section{Lista de Figuras}

2.1 Para o modelo de Nardi et al [37], caracterização dos estados fundamentais e linhas de coexistência para $T=0.10$

3.1 Um toro $\mathbb{T}_{N}$ é dividido nas correspondentes metades esquerda e direita através da linha de reflexão $P$, passando através dos sítios, i.e. $\vartheta_{P} \in \Theta^{0}$. . . . . . . . . . . . . . . . . . . . . . . . . . . . . . 16

3.2 Representação do campo externo (sítios brancos e pretos) e os $\Lambda$-blocos no toro. Linhas vermelhas indicam o conjunto $\mathcal{P}$ de linhas de reflexão. Neste caso $L_{1}=3$, e $L_{2}=2$. . . . . . . . . . . . . . . . . . . . 17

3.3 Representação do propagador $\pi_{\mathbf{t}}$. (a) Decomposição do toro em blocos, observe o $\Lambda$-evento $\mathcal{A}$. (b) Ilustração do evento resultante uma vez aplicado o propagador $\pi_{\mathbf{t}}(\mathcal{A})$, com $\mathbf{t}=\left(2 L_{1}, L_{2}\right)$. . . . . . . . . . . . . . 19

5.1 A subrede $\Lambda^{[2 \times 2]}$ é composta pelos sítios dentro do retângulo azul $\widehat{\Lambda}^{[2 \times 2]}$. Aqui $L_{1}=3$, e $L_{2}=2$. . . . . 39

5.2 (a) Representação de uma configuração $\sigma \in \Omega^{*}$. (b) A linha verde, formada por arestas do grafo dual, ilustra o correspondente contorno externo $\gamma^{\text {ext }}(\sigma)$. . . . . . . . . . . . . . . . . . . . . . . . . . . . . 44

$5.3 \mathrm{O}$ contorno de blocos associado à configuração $\sigma \in \Omega^{*}$ e o contorno externo $\gamma^{\text {ext }}(\sigma)$, definidos na Figura 5.2. Observe que este contorno é composto por seis $\Lambda$-blocos e um bloco-duplo, o qual contém dois $\Lambda$-blocos vizinhos com configurações $\sigma$-boas. . . . . . . . . . . . . . . . . . . . . . . . . . . . . . . . .

5.4 O modelo estudado na Seção $4.2 .3 \mathrm{com} L=2$. Este modelo pode ser considerado como um modelo do tipo cell-board com $L_{1}=\infty$, e $L_{2}=2$. . . . . . . . . . . . . . . . . . . . . . . . . . . . . . . . . 48 


\section{Capítulo 1}

\section{Introdução}

O foco principal deste trabalho é um dos modelos mais estudados na área de mecânica estatística, ou seja, o modelo de Ising. Tal modelo foi estudado pela primeira vez por Ernst Ising [29], em meados dos anos 20. Historicamente, o modelo de Ising tem desempenhado um papel fundamental no desenvolvimento da compreensão do ferromagnetismo e antiferromagnetismo. No entanto, hoje em dia, as aplicações da teoria de campos de Gibbs, e particularmente o modelo de Ising, não são apenas para explicar os fenômenos físicos, mas também ferramentas úteis em diferentes áreas, tais como redes neuronais [43, 44], a dinâmica dos terremotos [30, 48], ou processamento de imagens $[11,46]$, entre outros.

O modelo de Ising é diretamente relacionado com os conceitos de transição de fase. Nós definimos uma transição de fase como uma alteração qualitativa e de grande escala, no estado de um sistema, que é causada por uma pequena mudança em um parâmetro como a temperatura ou a pressão.

Uma das tarefas básicas da mecânica estatística matemática é encontrar uma abordagem rigorosa para várias transições de fase de primeira ordem em sistemas de spins em reticulados [7] (geralmente $\mathbb{Z}^{d}$ ). Normalmente, as transições de fase implicam um conjunto de problemas matemáticos nãotriviais específicos.

Em muitos modelos a transição de fase é um resultado da quebra espontânea da simetria do sistema. O modelo mais conhecido com este tipo de transição de fase é o modelo de Ising ferromagnético, na ausência de um campo magnético. Essencialmente, este fato foi demonstrado por Peierls [39]. Tornou-se um teorema nos trabalhos de Griffiths [26] e Dobrushin [13] (ver também [47] e [12]). As ideias de Peierls, atualmente chamadas de "argumento de Peierls", são baseadas em uma simetria do modelo de Ising. O argumento de Peierls mostra uma estabilidade dos estados fundamentais (ground states).

Os elementos essenciais do argumento são: a "condição de Peierls", e a "transformação de Peierls". A condição de Peierls significa que a energia necessária para a formação de um droplet de uma das fases, rodeado pelos lados com spins do valor oposto, é proporcional ao tamanho da fronteira do droplet. Para um modelo bidimensional (em $\mathbb{Z}^{2}$ ), o tamanho da fronteira é o comprimento da borda do droplet (também chamado de contorno). A condição de Peierls não está relacionada com a simetria do modelo. Isto porque ela é satisfeita para o modelo de Ising com campo externo uniforme, 
no entanto, a simetria é violada neste caso. O segundo componente do argumento de Peierls é construir uma transformação do espaço de configurações, que chamamos de transformação de Peierls, de tal modo que a energia de uma configuração em que existe um droplet, é mapeada para outra configuração em que o contorno é removido. Simetria do modelo é necessária para a construção da transformação de Peierls. O argumento de Peierls permite garantir que a probabilidade da presença de um contorno arbitrário é pequena a baixas temperaturas.

Ao contrário do argumento de Peierls, a teoria de Pirogov-Sinai das transições de fase [40, 41, $49,50]$, nos permite encontrar o diagrama de fases a baixa temperatura do modelo, sem exigência de simetria. Tal teoria proporciona também, um melhor controle sobre o número das medidas de Gibbs, estas associadas ao número dos estados fundamentais chamados "estáveis".

Além disso, existem várias abordagens. Uma dessas abordagens, Reflection Positivity (RP) [8, 10, 45], requer mostrar um tipo de simetria por reflexão no Hamiltoniano do modelo. Essencialmente, para provar uma transição de fase é possível construir uma adaptação do argumento de Peierls, usando a desigualdade de chessboard obtida a partir do estabelecimento da propriedade de RP no sistema.

Um campo externo imposto ao Hamiltoniano pode mudar o diagrama de fases completamente. No caso do modelo de Ising ferromagnético, qualquer campo externo uniforme não-nulo suprime a transição de fase. Em alguns modelos, onde o campo magnético é suposto não uniforme, é possível provar singularidade de fase. Ver, por exemplo, [9], e [10]. Um campo externo aleatório também pode suprimir a transição de fase num modelo de Ising em duas dimensões (ver [3], [4]), mesmo no caso em que a média total do campo externo é igual a 0.

Neste trabalho, iremos abordar o problema da existência de transição de fase em um modelo de Ising ferromagnético em $\mathbb{Z}^{2}$, quando o campo externo é periódico, formando uma configuração que emula um tabuleiro de xadrez (chamamos de cell-board configuration), de tal forma que o valor total do campo magnético é zero. Estes modelos foram numericamente estudados por M. Sigelle em [46] (ver também [36]). A motivação vem da área de processamento de imagens, em que os modelos de Ising com campos externos não uniforme são utilizados para a análise de segmentação. Entendendo que os valores, +1 e -1 do spin, irão representar as cores branco e preto.

Iremos considerar um modelo de Ising em que o campo externo assume dois valores: $h \mathrm{e}-h$, onde $h>0$. O reticulado $\mathbb{Z}^{2}$, é dividido na união de células retangulares disjuntas do mesmo tamanho, e os sinais do campo externo são dispostos de forma alternada, semelhante a um tabuleiro de xadrez. Especificamente, uma célula com um certo sinal do campo externo é rodeada por quatro células vizinhas com campo externo de valor oposto. Nós usamos um termo específico para esta partição, cell-board, para evitar a confusão com a estimativa de chessboard, a qual é usada na prova do nosso teorema principal.

Um caso particular desse tipo de modelos com campo externo alternado foi estudado por Nardi, Olivieri e Zahradník em [37]. Nesse trabalho, as células têm comprimento horizontal infinito, enquanto a sua altura é igual a um. Para este modelo Nardi et al. [37], provaram transição de fase usando uma modificação simples da transformação de Peierls. As ideias por eles usadas em geral não são aplicáveis ao nosso modelo de Ising de tipo cell-board. 


\subsection{Objetivos da tese}

O nosso principal objetivo de pesquisa é caracterizar o diagrama de fases a baixas temperaturas, para um modelo de Ising ferromagnético com campo externo periódico. Baseados na caracterização dos estados fundamentais, e a obtenção da condição de Peierls apresentada por Maruani et al. [36], focamos na prova de transição de fase na região de coexistência de dois estados fundamentais.

Procuramos interpretar e aplicar a técnica de reflection positivity. As simetrias do campo externo indicam que este método é o mais apropriado. A propriedade de RP permite provar transição de fase, construindo uma técnica de contornos similar às ideias do argumento de Peierls.

Como problema complementar, nos interessa a análise da região de unicidade. Neste sentido, propomos o estudo da técnica de disagreement percolation (ver [5], [6]), isto por causa dos elementos probabilísticos que participam da construção do critério de unicidade, a saber, as ideias de percolação de sítios e acoplamento de variáveis aleatórias.

\subsection{Organização do texto}

O texto é organizado da seguinte forma: no Capítulo 2 definimos o modelo em estudo e mencionamos outros dois modelos que possuem um vínculo com o modelo de Ising do tipo cell-board. As técnicas utilizadas, a saber, reflection positivity e disagreement percolation serão definidas no Capítulo 3. Especificamente enunciamos as estimativas de chessboard e o critério de unicidade. Os principais resultados são apresentados no Cap. 4, que incluem o Teorema de unicidade e o principal Teorema 4.2.1. As provas rigorosas estão incluídas no Capítulo 5. 


\section{Capítulo 2}

\section{Definição do Modelo e Enunciado do Problema}

Neste capítulo definimos um modelo de Ising que chamamos do tipo cell-board, este é um modelo ferromagnético com um campo externo periódico em forma de tabuleiro de xadrez. Inicialmente, o estudo da existência de transição de fase para este modelo é o nosso problema central. Porém, propomos incluir um estudo da região de unicidade como resultado complementar.

Primeiro definimos o modelo, o qual foi estudado por Maruani et al. [36] (ver também [25]). Além disso, mencionamos dois modelos que apresentam uma direta relação com os modelos de Ising do tipo cell-board. A saber, o Ising antiferromagnético com campo externo uniforme [15], e o modelo de Ising com campo externo alternado estudado em Nardi et al. [37].

Finalmente, fazendo uma revisão na literatura sobre os modelos de Ising com campo externo, propomos o estudo da técnica de reflection positivity e o método de disagreement percolation, para provar transição de fase e unicidade da medida de Gibbs, respectivamente.

\subsection{Modelo de Ising ferromagnético com campo externo do tipo cell-board}

Neste trabalho consideramos um modelo de Ising com campo externo periódico, o qual assume dois valores: $h$ e $-h$, em que $h>0$. O reticulado $\mathbb{Z}^{2}$ é dividido em células retangulares disjuntas do mesmo tamanho, e os sinais do campo externo são alternados, de forma similar a um tabuleiro de xadrez. Especificamente, uma célula com certo valor do campo externo ficará cercada por quatro retângulos vizinhos com campo externo de sinal oposto.

Estes modelos foram numericamente estudados por M. Sigelle em [46]. Posteriormente, uma caracterização rigorosa dos estados fundamentais foi apresentada por Maruani et al. em [36]. A motivação provém da área de processamento de imagens, onde os modelos de Ising com campo externo alternado são usados para a análise de segmentação.

Formalmente, consideramos o modelo de Ising ferromagnético em $\mathbb{Z}^{2}$, com campo externo periódico, definido em [36]. Representamos o reticulado $\mathbb{Z}^{2}$ como uma união disjunta de retângulos de 
tamanho $L_{1} \times L_{2}$ sítios, $L_{i} \in \mathbb{N}$ : para cada par de inteiros $n, m$, definimos

$$
\begin{aligned}
C(n, m)=\left\{\left(t_{1}, t_{2}\right) \in \mathbb{Z}^{2}: \quad\right. & n L_{1} \leq t_{1}<(n+1) L_{1}, \\
& \left.m L_{2} \leq t_{2}<(m+1) L_{2}\right\} .
\end{aligned}
$$

Então $\mathbb{Z}^{2}=\cup_{n, m \in \mathbb{Z}} C(n, m)$. Definimos os seguintes subconjuntos $\mathbf{Z}_{+}$e $\mathbf{Z}_{-}$de $\mathbb{Z}^{2}$.

$$
\mathbf{Z}_{+}=\bigcup_{\substack{n, m: \\ n+m \text { è par }}} C(n, m), \quad \mathbf{Z}_{-}=\mathbb{Z}^{2} \backslash \mathbf{Z}_{+} .
$$

Imaginemos que cada sítio é pintado da cor branca se pertence a $\mathbf{Z}_{+}$, e preto caso contrário. Então, o reticulado tem a forma de um tabuleiro de xadrez. (ver Figura 3.2, onde $L_{1}=3$, e $L_{2}=2$ ).

Seja $\Omega=\{-1,+1\}^{\mathbb{Z}^{2}}$ o conjunto de configurações em $\mathbb{Z}^{2}$. O Hamiltoniano formal é definido por

$$
H(\sigma)=-J \sum_{\langle t, s\rangle} \sigma(t) \sigma(s)-\sum_{s} h(s) \sigma(s),
$$

para todo $\sigma \in \Omega$, em que $\sigma(t)$ é o valor do spin da configuração $\sigma$ no sítio $t \in \mathbb{Z}^{2}, J>0$ é a constante de interação, o símbolo $\langle t, s\rangle$ denota vizinhos mais próximos $s, t \in \mathbb{Z}^{2}$, isto é a distância Euclideana entre os pontos é um, $|t-s|=1$, e o campo externo periódico $h(\cdot)$ é dado por

$$
h(s)=\left\{\begin{aligned}
h, & \text { se } s \in \mathbf{Z}_{+}, \\
-h, & \text { se } s \in \mathbf{Z}_{-},
\end{aligned}\right.
$$

em que $h>0$.

Para este modelo, Maruani et al. [36] apresentaram um estudo rigoroso sobre os estados fundamentais, isto é, definindo as fases do modelo à temperatura $T=0$. Na sequência, expomos este resultado. Porém, para tal motivo precisamos algumas definições e notações associadas.

Para cada subconjunto $\Lambda \subset \mathbb{Z}^{2}$ e toda configuração $\sigma \in \Omega$, usamos a notação $\sigma(\Lambda)$ para a configuração de $\sigma$ restrita ao conjunto de sítios $\Lambda$.

Além disso, dizemos que uma configuração $\tilde{\sigma} \in \Omega$, é uma perturbação local da configuração $\sigma \in \Omega$ se existir um conjunto finito $V \subset \mathbb{Z}^{2}$ tal que

$$
\tilde{\sigma}(t)=\left\{\begin{array}{rr}
-\sigma(t), & \text { se } t \in V, \\
\sigma(t), & \text { se } t \notin V .
\end{array}\right.
$$

Uma configuração $\sigma \in \Omega$ é chamada de estado fundamental (ground state) para o Hamiltoniano $H$, se, para toda perturbação local $\tilde{\sigma}$ da configuração $\sigma$, a desigualdade

$$
H(\tilde{\sigma})-H(\sigma) \geq 0
$$

é valida. Seguindo [36], dizemos que a condição de Peierls é verdadeira, se existe uma constate 
positiva $c_{P}>0$, tal que para cada perturbação local $\tilde{\sigma}$ de um estado fundamental $\sigma$, a desigualdade

$$
H(\tilde{\sigma})-H(\sigma) \geq c_{P}|\partial V|,
$$

vigora, em que $\partial V=\{\langle t, s\rangle: t \in V, s \notin V\}$, é a fronteira do conjunto $V$. A constante $c_{P}$ é chamada de constante de Peierls neste caso.

Também, iremos usar a noção de configuração periódica: dizemos que uma configuração $\sigma \in \Omega$ é periódica, se existe um retângulo finito

$$
A=\left\{t=\left(t_{1}, t_{2}\right): N^{\prime}<t_{1} \leq N^{\prime \prime}, M^{\prime}<t_{2} \leq M^{\prime \prime}\right\},
$$

tal que para cada inteiro $k_{1}, k_{2} \in \mathbb{Z}$ e todo $t \in A$

$$
\sigma(t)=\sigma\left(t+\left(k_{1}\left(N^{\prime \prime}-N^{\prime}\right), k_{2}\left(M^{\prime \prime}-M^{\prime}\right)\right)\right)
$$

O seguinte teorema é o resultado de [36] sobre os estados fundamentais. Maruani et al. [36] também garantiram a validade da condição de Peierls em (2.5).

Teorema 2.1.1. Se

$$
h<\frac{2 J}{L_{1}}+\frac{2 J}{L_{2}}
$$

então existem dois estados fundamentais periódicos, isto é, as configurações constantes $\sigma^{+} \equiv+1$ e $\sigma^{-} \equiv-1$. Além disso, a condição de Peierls é valida, e a constante de Peierls $c_{P}$ é igual a $2 J-h L_{1} L_{2} /\left(L_{1}+L_{2}\right)$. Se (2.8) não é valida e

$$
h>\frac{2 J}{L_{1}}+\frac{2 J}{L_{2}}
$$

então a configuração

$$
\sigma_{c}(t)=\left\{\begin{aligned}
1, & \text { se } t \in \mathbf{Z}_{+}, \\
-1, & \text { se } t \in \mathbf{Z}_{-},
\end{aligned}\right.
$$

é o único estado fundamental periódico.

\section{Medidas de Gibbs.}

A seguir lembramos algumas definições básicas sobre campos Markovianos e medidas de Gibbs no reticulado infinito $\mathbb{Z}^{2}$, e notações relacionadas.

Seja $W$ um subconjunto finito de $\mathbb{Z}^{2}$, e seja $\Omega_{W}$ o conjunto de todas as configurações em $W$ : $\Omega_{W}=\{-1,+1\}^{W}$. Nesta seção, os elementos de $\Omega_{W}$ serão denotados por $\sigma=(\sigma(i), i \in W)$ se diz respeito ao campo aleatório, e por $\eta, \eta^{\prime}, \ldots$, se considerarmos uma configuração fixa. Se $A \subset W \subset \mathbb{Z}^{2}, \eta, \eta^{\prime} \in \Omega_{W}$ e $\eta(i)=\eta^{\prime}(i)$ para todo $i \in A$, escrevemos " $\eta \equiv \eta^{\prime}$ em $A^{\prime}$. Além disso, $\partial A$ representará a fronteira de sítios do conjunto $A$. 
Consideramos certas medidas de probabilidade sobre $\Omega$, ou, mais precisamente, sobre a sigmaálgebra gerada pela coleção de conjuntos $\{\sigma \in \Omega: \sigma(i)=s\}, i \in \mathbb{Z}^{2}, s \in S=\{-1,+1\}$. Uma medida $\nu$ é chamada um campo de Markov se, para cada finito $A \subset \mathbb{Z}^{2}$ e cada $\eta \in S^{A}$,

$$
\nu\left[\sigma \equiv \eta \operatorname{em} A \mid \sigma(i), i \in A^{c}\right]=\nu[\sigma \equiv \eta \operatorname{em} A \mid \sigma(i), i \in \partial A], \quad \quad \nu-q . c .
$$

Agora, precisamos introduzir a chamada especificação $\left(Y_{A}(\cdot, \eta), A \subset \mathbb{Z}^{2}, \eta \in S^{\partial A}\right)$, que é um conjunto de medidas de probabilidade, indexado pelos conjuntos finitos $A \subset \mathbb{Z}^{2}$, e as possíveis configurações $\eta$ em $\partial A$, que chamaremos de condições de contorno.

Denote por $S_{\nu}^{\partial A}$ o conjunto de todas $\eta^{\prime} \in S^{\partial A}$ para as quais $\nu\left[\sigma \equiv \eta^{\prime}\right.$ em $\left.\partial A\right]>0$. Formalmente, o problema é determinar os campos de Markov $\nu$ que satisfazem, para todo finito $A \subset \mathbb{Z}^{2}$, todo $\eta \in S^{A}$ e todo $\eta^{\prime} \in S_{\nu}^{\partial A}$,

$$
\nu\left[\sigma \equiv \eta \text { em } A \mid \sigma \equiv \eta^{\prime} \text { em } \partial A\right]=Y_{A}\left(\eta, \eta^{\prime}\right)
$$

Estes campos de Markov são chamados de medidas de Gibbs da especificação $Y$. As noções aqui apresentadas serão utilizadas principalmente na Seção 3.2.

Particularmente, para o modelo de Ising do tipo cell-board, a medida de Gibbs da configuração $\sigma \in \Omega_{W}$ com condição de contorno $\omega \in \Omega$, é definida por

$$
\begin{aligned}
\mu_{\beta, W}(\sigma \mid \omega) & =\frac{1}{Z_{W}(\beta)} \exp \left(-\beta H_{W}(\sigma \mid \omega)\right) \\
& =\frac{1}{Z_{W}(\beta)} \exp \left(\beta J \sum_{\substack{\langle t, s\rangle: \\
t, s \in W}} \sigma(t) \sigma(s)+\beta J \sum_{\substack{\langle t, s\rangle: \\
t \in W, s \notin W}} \sigma(t) \omega(s)+\beta \sum_{s \in W} h(s) \sigma(s)\right),
\end{aligned}
$$

onde $\beta$ é uma constante positiva, usualmente interpretada como o inverso da temperatura, e

$$
Z_{W}(\beta)=\sum_{\sigma \in \Omega_{W}} \exp \left(-\beta H_{W}(\sigma \mid \omega)\right)
$$

é uma constante normalizadora, chamada de função de partição.

Quando $W \uparrow \mathbb{Z}^{2}$, de maneira adequada (para detalhes, ver [7]), obtemos o conjunto $\mathcal{G}_{\beta}$ de todas as medidas de Gibbs a volume infinito, para o Hamiltoniano (2.3) com temperatura inversa $\beta$.

O número de elementos do conjunto $\mathcal{G}_{\beta}$ é o foco principal deste trabalho. Então, para caracterizar a transição de fase usamos a definição a seguir.

Definição 1. Dizemos que o modelo apresenta uma transição de fase de primeira ordem sempre que os parâmetros são tais que $\left|\mathcal{G}_{\beta}\right|>1$.

Finalmente, vale lembrar que o nosso estudo considera três parâmetros. Por um lado, $J$ e $h$, os que vão definir o comportamento do Hamiltoniano (2.3), (2.4), isto é, os estados fundamentais do modelo. Por outro lado, o inverso da temperatura ou também denotado $\beta$, é o parâmetro para o qual caracterizamos o número de medidas de Gibbs (2.13), quando fixados $J, h>0$. 


\subsubsection{O modelo de Ising antiferromagnético com campo externo uniforme}

Expomos a relação entre o modelo acima definido e o modelo de Ising antiferromagnético com campo externo constante. Sabemos que o Hamiltoniano formal para o modelo antiferromagnético é

$$
H_{a}(\sigma)=-J_{a} \sum_{\langle t, s\rangle} \sigma(t) \sigma(s)-h_{a} \sum_{s} \sigma(s)
$$

onde o parâmetro $J_{a}$ é negativo, $J_{a}<0$, o que gera a interação antiferromagnética entre os sítios mais próximos, o campo externo $h_{a}$ é uma constante real.

Para $\left|h_{a}\right|<-4 J_{a}$, existem dois estados fundamentais $\sigma^{(1)}$ e $\sigma^{(2)}$,

$$
\begin{aligned}
\sigma^{(1)}(t) & =\left\{\begin{aligned}
1, & \text { se } t_{1}+t_{2} \text { é par, } \\
-1, & \text { se } t_{1}+t_{2} \text { é ímpar. }
\end{aligned}\right. \\
\sigma^{(2)}(t) & =-\sigma^{(1)}(t) .
\end{aligned}
$$

Dobrushin [14] provou a existência de transição de fase na região $\left|h_{a}\right|<-4 J_{a}$. Além disso, com ajuda de ferramentas computacionais, Dobrushin et al. [15] usaram um critério de unicidade para provar a existência de uma única medida de Gibbs em $\left|h_{a}\right|>4 J_{a}$. Este resultado de unicidade foi aprimorado por van den Berg [5], utilizando sua condição de unicidade obtida do método chamado de disagreement percolation.

Observação 1. Intuitivamente, o modelo de Ising com campo externo do tipo cell-board, \pm , quando $L_{1}=L_{2}=1$, deve ser equivalente ao modelo antiferromagnético $\left(J_{a}=-J\right)$ com campo externo constante $h_{a}=h$. Este fato será provado na Seção 4.2.2.

\subsubsection{Ising ferromagnético com campo externo alternado de Nardi et al. [37]}

O único trabalho, de que temos conhecimento, sobre o diagrama de fases a baixas temperaturas para um modelo de Ising com campo externo periódico é de Nardi, Olivieri e Zahradník [37]. Eles apresentam um diagrama de fases a baixas temperaturas para o modelo de Ising $2 \mathrm{D}$ com campo externo alternado em 1D. De outra forma, dizemos que o campo externo é

$$
h\left(s_{1}, s_{2}\right)=\left\{\begin{aligned}
h_{1}, & \text { se } s_{2} \text { é par, } \\
-h_{2}, & \text { se } s_{2} \text { é ímpar }
\end{aligned}\right.
$$

em que $h_{1}, h_{2}>0$.

Principalmente, três estados fundamentais distintos aparecem em diferentes regiões: tudo mais $\sigma_{+} \equiv+1$, tudo menos $\sigma_{-} \equiv-1$ e a configuração alternada $\sigma_{c} \equiv \pm 1$ com tudo mais (tudo menos) nas linhas pares (ímpares) do reticulado $\mathbb{Z}^{2}$, observe que esta configuração é criada pelo campo externo em (2.17). Estas regiões estão separadas pelas linhas de coexistência: i) $h_{1}>2 J, h_{2}=2 J$; ii) $h_{2}>2 J, h_{1}=2 J$; e iii) $h_{1}=h_{2}<2 J$. Ver Figura 2.1 . 


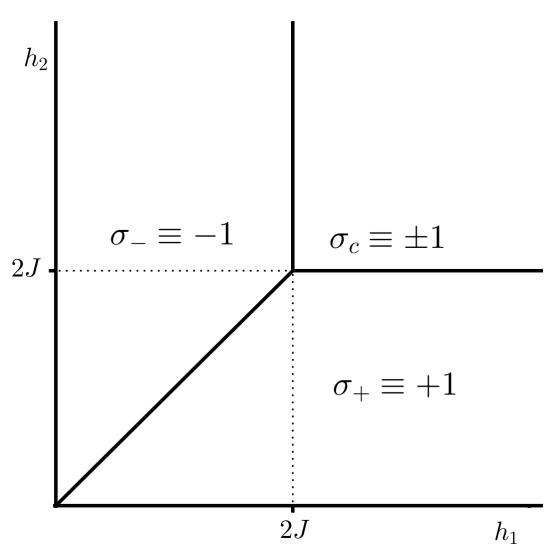

Figura 2.1: Para o modelo de Nardi et al [37], caracterização dos estados fundamentais e linhas de coexistência para $T=0$.

Usando um argumento de Peierls adaptado a este modelo, eles provaram transição de fase para todo $\beta>0$ em:

$$
\left\{\left(h_{1}, h_{2}\right): h_{1}=h_{2}<2 J-k e^{-\beta J}\right\},
$$

para alguma constante adequada $k>0$. O procedimento conclui com o estudo de um modelo de Ising ferromagnético com constantes de interação vertical $J_{1}=J$ e horizontal $J_{2}=J-h / 2$, respectivamente (ver Seção 3 de [37]).

Além disso, mediante a técnica de cluster expansion, eles obtiveram unicidade em:

$$
\left\{\left(h_{1}, h_{2}\right): \max \left\{h_{1}, h_{2}\right\}>2 J+k^{\prime} e^{-\beta J}\right\},
$$

para alguma constante positiva adequada $k^{\prime}$. Finalmente, eles conjecturaram unicidade da medida de Gibbs na região restante.

Observação 2. Na Seção 4.2.3 expomos um resultado que inclui a transição de fase na região em (2.18), a prova que apresentamos explora a propriedade de RP. De fato, note que o campo externo em (2.17), quando $h_{1}=h_{2}$, pode ser interpretado como sendo do tipo cell-board com $L_{1} \sim \infty e$ $L_{2}=1$. Porém, o Teorema 4.2.3 é valido para todo $L_{2} \geq 1$.

\subsection{Estudo do diagrama de fases a baixas temperaturas}

Na literatura encontram-se principalmente estudos sobre o modelo de Ising com campo externo uniforme, isto é $h(i) \equiv h, i \in \mathbb{Z}^{2}$. O resultado mais conhecido, baseado na teoria de Lee-Yang e na desigualdade de GHS (Griffiths-Hurst-Sherman), garante unicidade da medida de Gibbs para toda temperatura, quando $h \neq 0$ (ver [38, 42]). Esta ausência de transição de fase é definida pela diferenciabilidade da chamada energia livre com respeito ao parâmetro $h$. 
Alguns trabalhos sobre campos externos não uniformes incluem os estudos de Bissacot e Cioletti [9] e Bissacot et al. [10]. Este último analisa um campo espacialmente dependente. Ao contrário do campo de tipo cell-board estudado nesta tese, o campo em [10] é não periódico.

Notamos que o trabalho de Nardi et al. [37] representa um modelo diretamente relacionado com os modelos de Ising do tipo cell-board, dito campo é periódico e possui valor total igual a zero, quando $h_{1}=h_{2}$. A transição de fase por eles provada é baseada no argumento de Peierls. No caso, para construir a transformação de Peierls, é possível transladar o contorno verticalmente uma unidade, e trocar o valor dos spins dentro do contorno. Desta forma o flip e o campo externo equilibram-se (este método também aplica no modelo em (2.15)).

O foco desta tese é caracterizar a existência de transição de fase na região

$$
h<\frac{2 J}{L_{1}}+\frac{2 J}{L_{2}} .
$$

Ou seja, coexistência dos estados fundamentais $\sigma_{+}$e $\sigma_{-}$. Também procuramos obter uma estimativa da temperatura crítica. Propomos usar a técnica de Reflection Positivity, para explorar as simetrias do campo externo e pela impossibilidade de repetir as considerações feitas por Nardi et al. [37]. As ideias de RP que utilizaremos podem ser adaptadas para serem aplicadas a um modelo de faixas alternadas, que vem generalizar o modelo proposto em [37].

Com respeito à unicidade da medida de Gibbs no modelo, na região

$$
h>\frac{2 J}{L_{1}}+\frac{2 J}{L_{2}},
$$

procura-se estudar as ideias propostas por van den Berg [5], e aprimoradas em van den Berg e Maes [6], para obter uma condição de unicidade baseada em conceitos probabilísticos. Isto inclui, o modelo de percolação de sítios e acomplamento de variáveis aleatórias. Este método é conhecido como disagreement percolation [5, 6], e tem nos permitido obter uma região de unicidade de forma muito simples e direta, embora pouco precisa. Como pesquisas futuras deixamos a análise da região completa de unicidade (2.9), utilizando os métodos de cluster expansion [32, 18], ou a teoria de Pirogov-Sinai [49, 50, 34]. 


\section{Capítulo 3}

\section{Técnicas Aplicadas}

Neste capítulo, apresentamos duas técnicas utilizadas no estudo rigoroso do diagrama de fases a baixas temperaturas.

A primeira técnica, utilizada para provar transição de fase no modelo em estudo, é chamada reflection positivity (RP). Explicamos a técnica de RP de um modo adaptado ao nosso modelo. Revisões mais aprofundadas podem ser encontradas nos trabalhos de Georgii [23], e particularmente Shlosman [45]. Neste capítulo, usamos principalmente as notações e definições de Biskup e Kotecký [8] e de Biskup [7]. A principal consequência desta técnica é a estimativa de chessboard, que é uma ferramenta essencial para provar transição de fase em modelos que possuem a propriedade de RP.

De forma complementar, propomos a aplicação de um critério de unicidade para estudar a região em (2.9). Este critério é obtido das propriedades de um acoplamento de duas realizações do modelo, cada com diferente condição de contorno. O controle da chamada distância variacional é de principal interesse, esta é comparada com a probabilidade crítica de um modelo de percolação de sítios. Van den Berg [5] chamou estas ideias de disagreement percolation.

\subsection{A propriedade de Reflection Positivity (RP)}

Nesta seção, descrevemos um enfoque matemático bem-sucedido no estudo de transições de fase em modelos de spins em reticulados. Este é baseado na técnica de reflection positivity. Esta técnica foi desenvolvida no final dos anos 70, nos trabalhos inovadores de F. Dyson, J. Fröhlich, R. Israel, E. Lieb, B. Simon e T. Spencer [24, 22, 21, 19, 17, 20], que a usaram para estabelecer transições de fase em uma série de modelos de spins em reticulados fisicamente interessantes, no contexto clássico como quântica: mais concretamente, o ferromagneto clássico de Heisenberg, e o modelo quântico $X Y$.

O sucesso espetacular de reflection positivity a partir do final dos anos 1970, foi seguido por muitos desenvolvimentos interessantes. Por exemplo, em várias colaborações, R. Dobrushin, R. Kotecký e S. Shlosman [16, 33], provaram que as estimativas de chessboard podem ser usadas para provar a transição de fase em uma classe de sistemas com componentes de ordem e desordem naturalmente definidos: por exemplo, o modelo de $q$ estados de Potts, para $q>>1$. Outra interessante aplicação 
veio dos artigos de M. Aizenman (ver [1] e [2]), em que combinam-se o método do limite infravermelho (infrared bound), baseado em RP, com a sua representação de random current, para concluir o comportamento crítico da magnetização no modelo de Ising ferromagnético em dimensões acima de 4.

A característica mais interessante do método de reflection positivity, especialmente comparado com técnicas alternativas, é a simplicidade das provas resultantes. Existem dois tipos de argumentos que podem ser usados: o primeiro é chamado de limite infravermelho, e afirma em termos quantitativos, que as flutuações das variáveis de spin são dominadas por aquelas de um campo livre Gaussiano no reticulado (para detalhes, ver [7]). Em sistemas com uma simetria interna, isto produz a prova da transição de fase por quebra de simetria, por meio de um argumento de spin-condensação. Outro argumento passa através das chamadas estimativas de chessboard, que nos permitem implementar um argumento do tipo Peierls, independentemente do modelo exibir ou não uma simetria interna.

Os nossos resultados são essencialmente baseados na aplicação das estimativas de chessboard. A seguir, definimos a notação e os elementos matemáticos a serem utilizados. Assim, construímos e apresentamos as estimativas de cheesboard na seguinte seção.

\subsubsection{Estimativa de chessboard e transição de fase}

Primeiramente, junto com o reticulado $\mathbb{Z}^{2}$, consideramos o grafo

$$
\mathbb{G}=\left(\mathbb{Z}^{2}, \mathbb{E}\right),
$$

onde $\mathbb{E}$ é um conjunto de arestas entre vizinhos mais próximos.

A seguir, precisamos colocar o sistema de spins sobre um toro bidimensional. Seja $T_{N}=$ $T_{N}\left(L_{1}, L_{2}\right)$, um subconjunto de $\mathbb{Z}^{2}$ de tamanho $N L_{1} \times N L_{2}$ :

$$
T_{N}=\left\{t=\left(t_{1}, t_{2}\right) \in \mathbb{Z}^{2}: 0 \leq t_{1}<N L_{1}, 0 \leq t_{2}<N L_{2}\right\}
$$

Daqui em diante, por questões técnicas supomos $N$ par. Assim, note que $T_{N}$ é composto por $N^{2} / 2$ células de $\mathbf{Z}_{+}$, e a mesma quantidade do tipo $\mathbf{Z}_{-}$.

Iremos considerar $T_{N}$ como um toro. Dizemos que para cada inteiro $x: 0 \leq x<N L_{1}$, os sítios $(x, 0)$ e $\left(x, N L_{2}-1\right)$, são vizinhos. Além disso, para cada inteiro $y: 0 \leq y<N L_{2}$, os sítios $(0, y)$ e $\left(N L_{1}-1, y\right)$, são vizinhos. O conjunto $T_{N}$ com esta definição de vizinhos será denotado por $\mathbb{T}_{N}$, ou em outras palavras, o toro $\mathbb{T}_{N}$ pode ser definido como o grupo quociente $\mathbb{T}_{N}:=\mathbb{Z} /\left(N L_{1} \mathbb{Z}\right) \times \mathbb{Z} /\left(N L_{2} \mathbb{Z}\right)$.

Assumimos que $\mathbb{T}_{N}$ esteja embutido no toro contínuo $\widehat{\mathbb{T}}_{N}$, ou seja,

$$
\widehat{\mathbb{T}}_{N}=\mathbb{R}^{2} /\left[\left(N L_{1} \mathbb{Z}\right) \times\left(N L_{2} \mathbb{Z}\right)\right]
$$

Denote $\Omega_{N}=\{-1,+1\}^{\mathbb{T}_{N}}$, sendo o conjunto de todas as configurações no toro $\mathbb{T}_{N}$. Consideramos 
o Hamiltoniano $H_{N}$, com as chamadas condições de contorno periódicas: para cada $\sigma \in \Omega_{N}$

$$
H_{N}(\sigma)=-J \sum_{\langle t, s\rangle \in \mathbb{T}_{N}} \sigma(t) \sigma(s)-\sum_{s \in \mathbb{T}_{N}} h(s) \sigma(s)
$$

em que $J>0$, e $h(s)$ é definido como em (2.4).

A medida de Gibbs no toro é dada por

$$
\mu_{\beta, N}(\sigma)=\frac{1}{Z_{N}(\beta)} \exp \left(\beta J \sum_{\langle t, s\rangle \in \mathbb{T}_{N}} \sigma(t) \sigma(s)+\beta \sum_{s \in \mathbb{T}_{N}} h(s) \sigma(s)\right),
$$

em que $\beta>0$, é o inverso da temperatura, e $Z_{N}(\beta)$ é a correspondente função de partição

$$
Z_{N}(\beta)=\sum_{\sigma \in \Omega_{N}} \exp \left(-\beta H_{N}(\sigma)\right)
$$

A seguir, enunciamos a propriedade de RP definida para as medidas no toro.

\section{Reflection positivity.}

Precisamos definir reflexões de simetria com respeito às retas ortogonais a uma das direções do reticulado. Assumimos o reticulado $\mathbb{Z}^{2}$ embutido em $\mathbb{R}^{2}$. Denotamos por $\Theta$, o grupo de transformações de $\mathbb{R}^{2}$, geradas por reflexões de $\mathbb{R}^{2}$, com respeito às retas ortogonais a uma das direções do reticulado, tal que $\mathbb{Z}^{2}$ é invariante para toda $\vartheta \in \Theta: \vartheta\left(\mathbb{Z}^{2}\right)=\mathbb{Z}^{2}$. Seja $\vartheta_{P}$, a reflexão $\vartheta$ com respeito à linha $P$. O grupo $\Theta$, é composto por dois subgrupos distintos $\Theta^{k}(k=0,1 / 2)$, gerados pelas reflexões $\vartheta_{P_{i}^{(n, k)}}$, para as quais as correspondentes linhas são

$$
P_{i}^{(n, k)}=\left\{t=\left(t_{1}, t_{2}\right) \in \mathbb{R}^{2}: t_{i}=n+k\right\}
$$

para $i=1$ ou 2 , todo inteiro $n$, e $k=0$ ou $1 / 2$. Reflexões em $\Theta^{0}$, serão chamadas de reflexões através de sítios: as correspondentes linhas de reflexão passam através dos sítios de $\mathbb{Z}^{2}$. As reflexões do conjunto $\Theta^{1 / 2}$, são chamadas de reflexões através de arestas: as correspondentes linhas de reflexão bissectam arestas de $\mathbb{E}$ em (3.1).

Os grupos $\Theta^{k}, k=0,1 / 2$, naturalmente geram as reflexões dos toros $\widehat{\mathbb{T}}_{N}$ e $\mathbb{T}_{N}$. Então, dizemos que $\vartheta_{P}\left(\widehat{\mathbb{T}}_{N}\right)=\widehat{\mathbb{T}}_{N}$ e $\vartheta_{P}\left(\mathbb{T}_{N}\right)=\mathbb{T}_{N}$. A linha de reflexão $P$ em $\mathbb{Z}^{2}$, torna-se duas linhas antípodas no toro, dividindo o toro em dois componentes simétricos, digamos $\mathbb{T}_{N}^{l}$ e $\mathbb{T}_{N}^{r}$, as metades esquerda e direita, respectivamente. Denotamos estas linhas com o símbolo $P$, assim como a reflexão $\vartheta_{P} \in \Theta^{k}$, entre as metades direita e esquerda tal que $\vartheta_{P}\left(\mathbb{T}_{N}^{l}\right)=\mathbb{T}_{N}^{r}$, e vice versa (ver Figura 3.1). Note que $\mathbb{T}_{N}^{l} \cap \mathbb{T}_{N}^{r} \in P$, para reflexões através dos sítios $(k=0)$, e são disjuntos para as reflexões através de $\operatorname{arestas}(k=1 / 2)$.

Seja $\mathcal{F}_{P}^{l}\left(\mathcal{F}_{P}^{r}\right)$ a $\sigma$-álgebra em $\Omega_{N}$, gerada por todas as funções $\sigma(t), t \in \mathbb{T}_{N}^{l}\left(\mathbb{T}_{N}^{r}\right)$. Como em Biskup e Kotecký [8], apresentamos um operador de reflexão $\theta_{P}: \Omega_{N} \rightarrow \Omega_{N}: \theta_{P}(\sigma(s)):=\sigma\left(\vartheta_{P}(s)\right)$, para a reflexão espacial $\vartheta_{P}: \mathbb{T}_{N}^{l} \leftrightarrow \mathbb{T}_{N}^{r}$. O operador $\theta_{P}$ obedece as seguintes propriedades: 

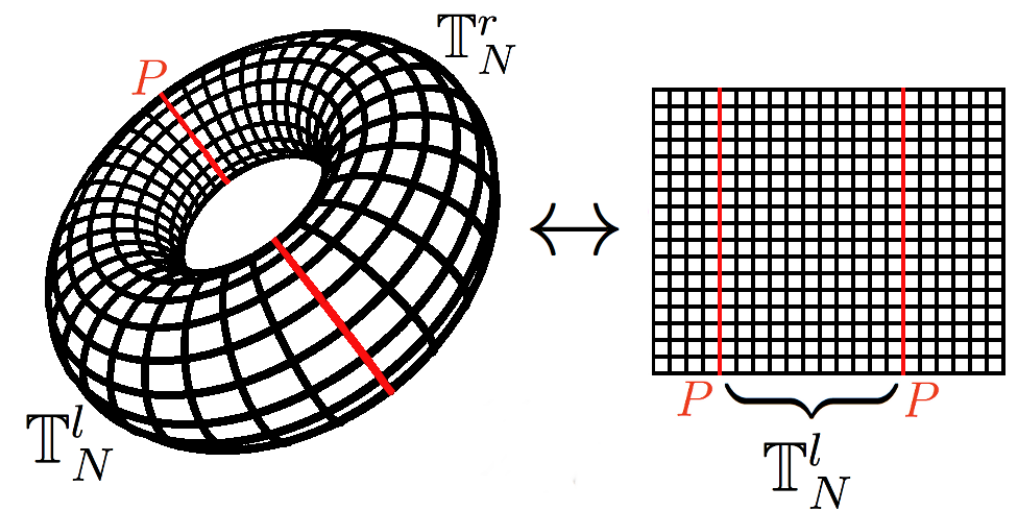

Figura 3.1: Um toro $\mathbb{T}_{N}$ é dividido nas correspondentes metades esquerda e direita através da linha de reflexão $P$, passando através dos sítios, i.e. $\vartheta_{P} \in \Theta^{0}$.

(1) $\theta_{P}$ é uma involução, $\theta_{P} \circ \theta_{P}=i d$;

(2) $\theta_{P}$ é uma reflexão no sentido que se $\mathcal{A} \in \mathcal{F}_{P}^{l}$, depende apenas de configurações em $\Lambda \subset \mathbb{T}_{N}^{l}$, então $\theta_{P}(\mathcal{A}) \in \mathcal{F}_{P}^{r}$, depende apenas de configurações sobre $\vartheta_{P}(\Lambda)$.

Uma vez definido o operador de reflexão, podemos enunciar a propriedade de RP.

Definição 2. (Reflection Positivity, ver Definição 2.2 de [8]). Seja $\mu$ uma medida de probabilidade em $\Omega_{N}$, denote $\mathrm{E}_{\mu}$ a correspondente esperança, e seja $P$ uma linha de reflexão. Dizemos que $\mu$ é uma medida positiva por reflexão (RP) com respeito a $\theta_{P}$, se para quaisquer duas funções limitadas $\mathcal{F}_{P}^{l}$-mensuráveis $f$ e $g$,

$$
\mathrm{E}_{\mu}\left(f \theta_{P}(g)\right)=\mathrm{E}_{\mu}\left(g \theta_{P}(f)\right),
$$

$e$

$$
\mathrm{E}_{\mu}\left(f \theta_{P}(f)\right) \geq 0
$$

onde $\theta_{P}(f)$ é a função $\mathcal{F}_{P}^{r}$-mensurável $f \circ \theta_{P}$.

Uma consequência da propriedade RP é uma desigualdade como a desigualdade de CauchySchwarz

$$
\left[\mathrm{E}_{\mu}\left(f \theta_{P}(g)\right)\right]^{2} \leq \mathrm{E}_{\mu}\left(f \theta_{P}(f)\right) \mathrm{E}_{\mu}\left(g \theta_{P}(g)\right) .
$$

Este resultado é uma preliminar da obtenção da estimativa de chessboard. Dizemos que, de certa forma, a desigualdade de chessboard estende (3.9).

\section{Desigualdade de chessboard.}

Em seguida, lembramos que as estimativas de chessboard serão aplicadas ao nosso caso. As simetrias de $\mathbb{T}_{N}$ que são usadas para estas aplicações estão relacionadas às simetrias do campo 
externo. Uma vez que o campo externo é periódico, qualquer transformação de simetria deve manter o período dos retângulos. As transformações de simetria de $\mathbb{T}_{N}$, são reflexões de $\mathbb{T}_{N}$, com relação às linhas sobre $\widehat{\mathbb{T}}_{N}$. Seja $\mathcal{P}=\mathcal{P}_{1} \cup \mathcal{P}_{2}$, um conjunto dessas linhas, sendo a união das linhas

$$
P_{i}^{(n)}=\left\{t=\left(t_{1}, t_{2}\right) \in \mathbb{R}^{2}: t_{i}=n L_{i}+\left(L_{i}-1\right) / 2\right\}, i=1,2,
$$

em que $n$ é um inteiro positivo menor que $N$, e $\mathcal{P}_{1}=\left\{P_{1}^{(n)}\right\}$, e $\mathcal{P}_{2}=\left\{P_{2}^{(n)}\right\}$.

Observe que, se $L_{i}$ é ímpar, então a correspondente reflexão $\vartheta_{P_{i}^{(n)}} \in \Theta^{0}$, e se $L_{i}$ é par, a correspondente reflexão $\vartheta_{P_{i}^{(n)}} \in \Theta^{1 / 2}$. Toda linha corta pela metade cada correspondente célula $C(n, m)$ (ver (2.1)). O conjunto de linhas $\mathcal{P}$, fornece uma decomposição de $\mathbb{T}_{N}$ em blocos retangulares (veja a Figura 3.2). Note que a soma total do campo externo dentro de cada bloco é igual a zero.

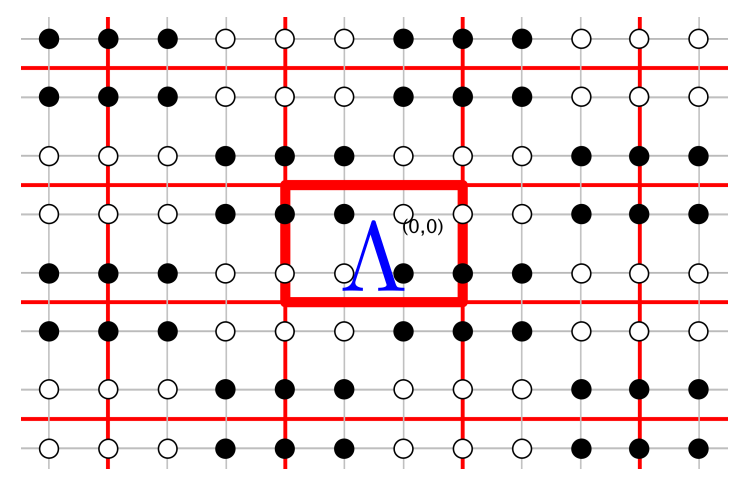

Figura 3.2: Representação do campo externo (sitios brancos e pretos) e os $\Lambda$-blocos no toro. Linhas vermelhas indicam o conjunto $\mathcal{P}$ de linhas de reflexão. Neste caso $L_{1}=3$, e $L_{2}=2$.

Seja $\Lambda$ o mínimo bloco obtido com divisões de $\mathcal{P}$, o qual contém a origem, isto é

$$
\Lambda=\left\{\left(t_{1}, t_{2}\right) \in \mathbb{T}_{N}:\left|t_{1}+\frac{1}{2}\right| \leq \frac{L_{1}}{2},\left|t_{2}+\frac{1}{2}\right| \leq \frac{L_{2}}{2}\right\} .
$$

O correspondente bloco $\widehat{\Lambda}$ em $\widehat{\mathbb{T}}_{N}$ é

$$
\widehat{\Lambda}=\left\{\left(r_{1}, r_{2}\right) \in \widehat{\mathbb{T}}_{N}:\left|r_{1}+\frac{1}{2}\right| \leq \frac{L_{1}}{2},\left|r_{2}+\frac{1}{2}\right| \leq \frac{L_{2}}{2}\right\}
$$

Note que o bloco $\Lambda$ contém $B_{1} \times B_{2}$ sítios, onde

$$
B_{i}=\left\{\begin{aligned}
L_{i}, & \text { se } L_{i} \text { é par, } \\
L_{i}+1, & \text { se } L_{i} \text { é ímpar. }
\end{aligned}\right.
$$

O toro $\widehat{\mathbb{T}}_{N}$, pode ser coberto por translações de $\widehat{\Lambda}$,

$$
\widehat{\mathbb{T}}_{N}=\bigcup_{\mathbf{r} \in \widetilde{\mathbb{T}}_{N}}(\widehat{\Lambda}+\mathbf{r})
$$

em que $\widetilde{\mathbb{T}}_{N}=\left\{\mathbf{r}=\left(r_{1}, r_{2}\right) \in \widehat{\mathbb{T}}_{N}: r_{1}=n L_{1}, r_{2}=m L_{2}, n, m \in \mathbb{Z}\right\}$, é um subgrupo quociente de 
$\mathbb{T}_{N}$. De maneira análoga, o toro $\mathbb{T}_{N}$ pode ser coberto por conjuntos $(\widehat{\Lambda}+\mathbf{r}) \cap \mathbb{T}_{N}$ :

$$
\mathbb{T}_{N}=\bigcup_{\mathbf{t} \in \widetilde{\mathbb{T}}_{N}}(\Lambda+\mathbf{t})
$$

As translações de $\Lambda$ que resultam ser vizinhas podem ter um lado em comum. Seja $\Omega(\Lambda)=\left\{\sigma_{\Lambda}\right\}$, o conjunto de todas as configurações definidas em $\Lambda$, e seja $\mathcal{F}_{\Lambda}$ uma $\sigma$-álgebra de eventos em $\Omega(\Lambda)$. Denotamos por $\Lambda$-evento os eventos $\mathcal{A} \in \mathcal{F}_{\Lambda}$.

Em seguida, apresentamos algumas noções. Para cada $s \in \mathbb{T}_{N}$, a aplicação $\tau_{s}: \Omega_{N} \rightarrow \Omega_{N}$, é uma translação por $s$, definida como $\left(\tau_{s} \sigma\right)(t)=\sigma(t-s)$. Defina também, as reflexões $\vartheta_{Q_{1}}$ e $\vartheta_{Q_{2}}$, onde

$$
Q_{i}=\left\{\left(t_{1}, t_{2}\right): t_{i}=-\frac{1}{2}\right\}, i=1,2,
$$

estas estão fora de $\mathcal{P}$. Além disso, essas reflexões não mudam $\Lambda$, e se $\sigma \in \Omega(\Lambda)$, os operadores de reflexão correspondentes não preservam a energia

$$
H(\sigma)-H\left(\theta_{Q_{i}}(\sigma)\right)=-2 \sum_{t \in \Lambda} h(t) \sigma(t)
$$

A continuação, um operador de propagação $\pi_{\mathbf{t}}$ em $\Omega_{N}$, com $\mathbf{t}=\left(n_{1} L_{1}, n_{2} L_{2}\right) \in \widetilde{\mathbb{T}}_{N}$, é definido com ajuda de dois operadores

$$
j_{\mathbf{t}}^{(i)}= \begin{cases}\theta_{Q_{i}}, & \text { se } n_{i} \text { é ímpar } \\ \mathbf{1}, & \text { caso contrário }\end{cases}
$$

em que o símbolo $\mathbf{1}$, representa o operador identidade, $\mathbf{1}(\sigma)=\sigma$.

Então, tal operador de propagação é dado por

$$
\pi_{\mathbf{t}}(\sigma)=\tau_{\mathbf{t}} \circ j_{\mathbf{t}}^{(1)} \circ j_{\mathbf{t}}^{(2)}(\sigma) .
$$

A configuração $\sigma$ é deslocada de tal forma que os seus valores em $\Lambda$ são movidos para $\Lambda+\mathbf{t}$, com as possíveis reflexões $\theta_{Q_{1}}$ e $\theta_{Q_{2}}$, dependendo das paridades de $t_{1}$ e $t_{2}$. O evento $\pi_{\mathbf{t}}(\mathcal{A})$, é um conjunto cilíndrico de configurações a partir de $\mathcal{F}_{\Lambda+\mathbf{t}}$.

Seja $\Pi_{\widetilde{\mathbb{T}}_{N}}$ o conjunto de todas as propagações correspondentes ao toro $\widetilde{\mathbb{T}}_{N}$. Toda propagação $\pi_{\mathbf{t}} \in \Pi_{\widetilde{\mathbb{T}}_{N}}$, é uma bijeção

$$
\sigma \in \Omega(\Lambda) \leftrightarrow \pi_{\mathbf{t}}(\sigma) \in \Omega(\Lambda+\mathbf{t})
$$

Assim, podemos usar o mapa inverso $\pi_{\mathbf{t}}^{-1}$. Uma ilustração do propagador que acabamos de definir pode-se encontrar na Figura 3.3.

A construção dos propagadores acima, está bem definida se trabalhamos no caso quando ambos $L_{1}$ e $L_{2}$ são ímpares. Nós, adicionalmente, precisamos de outra construção dos propagadores para os casos em que $L_{1}$ ou $L_{2}$ ou ambos são pares. Por exemplo, quando $L_{1}$ é par, as linhas verticais de 


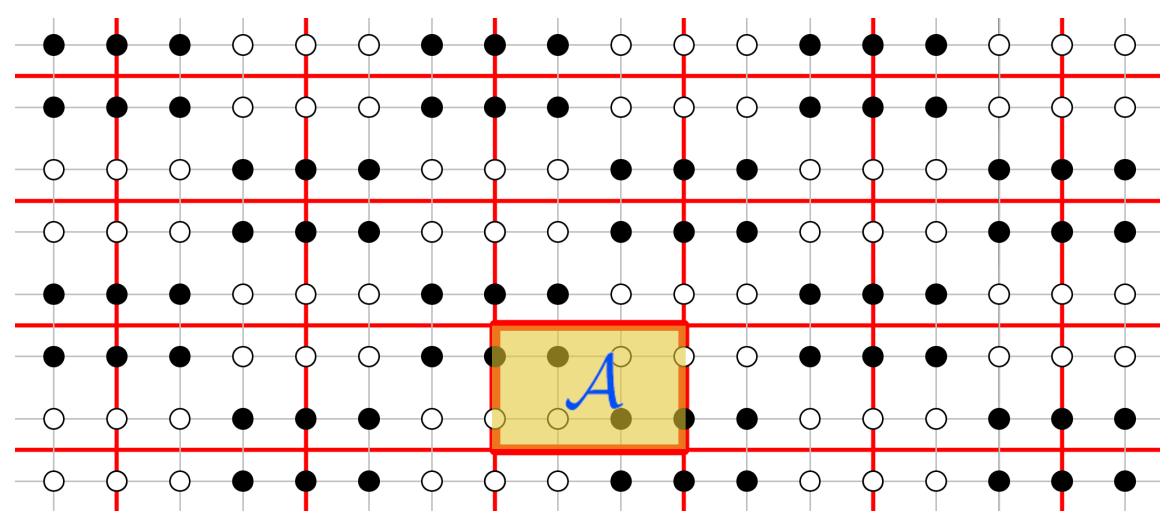

(a)

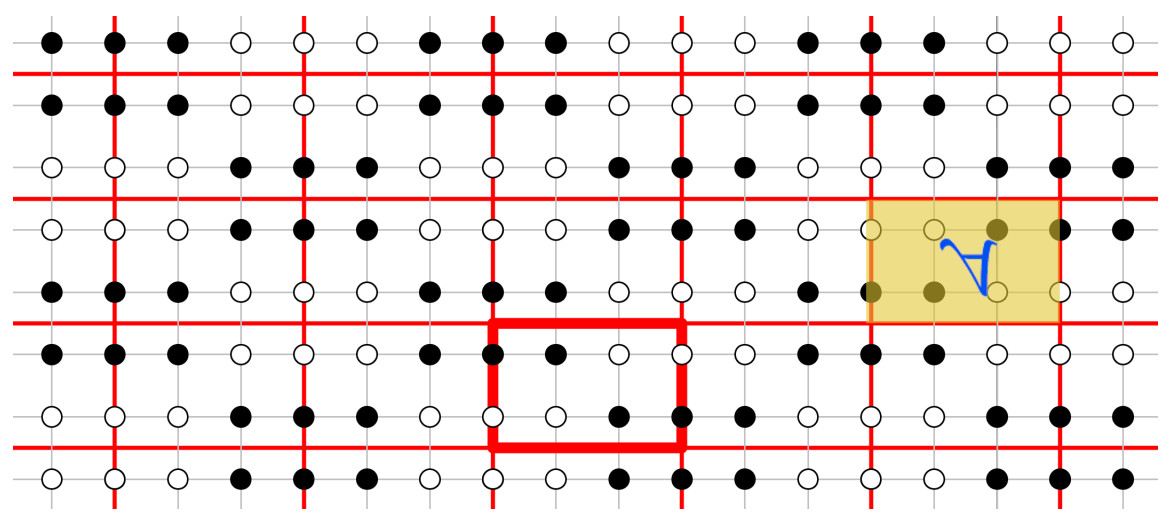

(b)

Figura 3.3: Representação do propagador $\pi_{\mathbf{t}}$. (a) Decomposição do toro em blocos, observe o $\Lambda$-evento $\mathcal{A}$. (b) Ilustração do evento resultante uma vez aplicado o propagador $\pi_{\mathbf{t}}(\mathcal{A})$, com $\mathbf{t}=\left(2 L_{1}, L_{2}\right)$.

reflexão bissectam as arestas de $\mathbb{Z}^{2}$. Como veremos mais tarde, neste caso considerações adicionais são necessárias quando construímos o argumento de Peierls.

As seguintes definições estão associadas com o caso quando $L_{1}$ é par, independentemente da paridade de $L_{2}$. O caso quando $L_{2}$ é par leva a uma construção similar. O primeiro fato na construção adicional, em vez de $\Lambda$ o bloco que será propagado é composto por um par de blocos vizinhos (ver (3.11)). Este par de blocos é chamado de bloco-duplo ou $\Lambda^{*}$-bloco. Mais precisamente, denotamos

$$
\Lambda_{1}^{*}=\Lambda \cup\left(\Lambda+\left(L_{1}, 0\right)\right) .
$$

As linhas verticais que refletem $\Lambda^{*}$, serão definidas por

$$
P_{1}^{\left(2 n, \frac{1}{2}\right)}=\left\{\left(t_{1}, t_{2}\right) \in \mathbb{R}^{2}: t_{2}=2 n+\frac{1}{2}\right\},
$$

(cf. com (3.10)). Assim, denotamos

$$
\mathcal{P}_{1}^{*}=\left\{P_{1}^{\left(2 n, \frac{1}{2}\right)}, n \in \mathbb{Z}\right\} .
$$


Qualquer evento definido por valores $\sigma(t)$ para $t \in \Lambda^{*}$, é chamado $\Lambda^{*}$-evento, e $\mathcal{F}_{\Lambda^{*}}$ é uma $\sigma$-álgebra de todos aqueles eventos. Seja $\Omega\left(\Lambda^{*}\right)$ o conjunto de todas as configurações em $\Lambda^{*}$.

Em seguida, definimos os propagadores das configurações de $\Omega\left(\Lambda^{*}\right)$. Para este fim, apresentamos um subgrupo

$$
\widetilde{\mathbb{T}}_{N}^{(1)}=\left\{\mathbf{t}=\left(t_{1}, t_{2}\right) \in \widetilde{\mathbb{T}}_{N}: t_{1}=2 L_{1} n, t_{2}=L_{2} m\right\}
$$

A linha de reflexão

$$
Q_{1}^{*}=\left\{\left(t_{1}, t_{2}\right): t_{1}=\frac{L_{1}-1}{2}\right\}
$$

e os operadores

$$
j_{\mathbf{t}}^{*(1)}= \begin{cases}\theta_{Q_{1}^{*}}, & \text { se } n \text { é ímpar } \\ \mathbf{1}, & \text { caso contrário, }\end{cases}
$$

em que $\mathbf{t}=\left(2 n L_{1}, m L_{2}\right) \in \widetilde{\mathbb{T}}_{N}^{(1)}(\mathrm{cf} .(3.15),(3.16))$. Finalmente, o propagador é

$$
\pi_{\mathbf{t}}^{*(1)}(\sigma)=\tau_{\mathbf{t}} j_{\mathbf{t}}^{*(1)} j_{\mathbf{t}}^{(2)}
$$

Observamos que, nesta situação, o operador $j_{\mathbf{t}}^{(2)}$, é definido em (3.16). Isso significa que as reflexões verticais são dadas como em (3.17). O conjunto dos propagadores é

$$
\Pi_{\widetilde{\mathbb{T}}_{N}^{(1)}}=\left\{\pi_{\mathbf{t}}^{*(1)}: \mathbf{t} \in \widetilde{\mathbb{T}}_{N}^{(1)}\right\}
$$

Por outro lado, no caso em que $L_{2}$ é par, todas as construções são semelhantes às acima definidas. O bloco-duplo agora é

$$
\Lambda_{2}^{*}=\Lambda \cup\left(\Lambda+\left(0, L_{2}\right)\right) .
$$

Um conjunto de linhas verticais que refletem $\Lambda_{2}^{*}$ é

$$
\mathcal{P}_{2}^{*}=\left\{P_{2}^{\left(2 n, \frac{1}{2}\right)}, n \in \mathbb{Z}\right\}
$$

em que

$$
P_{2}^{\left(2 n, \frac{1}{2}\right)}=\left\{\left(t_{1}, t_{2}\right) \in \mathbb{R}^{2}: t_{1}=2 n+\frac{1}{2}\right\} .
$$

O subgrupo correspondente é

$$
\widetilde{\mathbb{T}}_{N}^{(2)}=\left\{\mathbf{t}=\left(t_{1}, t_{2}\right) \in \widetilde{\mathbb{T}}_{N}: t_{1}=L_{1} n, t_{2}=2 L_{2} m\right\}
$$

Novamente, como no caso anterior, a linha de reflexão é

$$
Q_{2}^{*}=\left\{\left(t_{1}, t_{2}\right): t_{2}=\frac{L_{2}-1}{2}\right\},
$$


e os operadores são

$$
j_{\mathbf{t}}^{*(2)}= \begin{cases}\theta_{Q_{2}^{*}}, & \text { se } m \text { é ímpar } \\ \mathbf{1}, & \text { caso contrário, }\end{cases}
$$

onde $\mathbf{t}=\left(n L_{1}, 2 m L_{2}\right) \in \widetilde{\mathbb{T}}_{N}^{(2)}($ cf. (3.15), (3.16)). Por fim, o propagador é

$$
\pi_{\mathbf{t}}^{*(2)}(\sigma)=\tau_{\mathbf{t}} j_{\mathbf{t}}^{(1)} j_{\mathbf{t}}^{*(2)}
$$

O conjunto dos propagadores quando $L_{2}$ é par, é dado por

$$
\Pi_{\widetilde{\mathbb{T}}_{N}^{(2)}}=\left\{\pi_{\mathbf{t}}^{*(2)}: \mathbf{t} \in \widetilde{\mathbb{T}}_{N}^{(2)}\right\}
$$

Finalmente, estamos em condições de definir as desigualdades de chessboard.

Teorema 3.1.1. (Chessboard estimates, $[7,8,45]$ ) Seja $\mu_{\beta, N}$ uma medida sobre $\Omega_{N}$, que é RP com respeito a todas as reflexões entre os blocos vizinhos $(\Lambda+\mathbf{t}), \mathbf{t} \in \widetilde{\mathbb{T}}_{N}$. Então, para cada $\Lambda$-eventos $\mathcal{A}_{1}, \ldots, \mathcal{A}_{m}$ e conjunto de sítios distintos $\mathbf{t}_{1}, \ldots, \mathbf{t}_{m} \in \widetilde{\mathbb{T}}_{N}$,

$$
\mu_{\beta, N}\left(\bigcap_{j=1}^{m} \pi_{\mathbf{t}_{j}}\left(\mathcal{A}_{j}\right)\right) \leq \prod_{j=1}^{m} \mu_{\beta, N}\left(\bigcap_{\mathbf{t} \in \widetilde{\mathbb{T}}_{N}} \pi_{\mathbf{t}}\left(\mathcal{A}_{j}\right)\right)^{1 /\left|\widetilde{\mathbb{T}}_{N}\right|} .
$$

Além disso, para cada $\Lambda^{*}$-eventos $\mathcal{A}_{1}, \ldots, \mathcal{A}_{m}$ e sítios distintos $\mathbf{t}_{1}, \ldots, \mathbf{t}_{m} \in \widetilde{\mathbb{T}}_{N}^{(i)}$, com $i=1,2$,

$$
\mu_{\beta, N}\left(\bigcap_{j=1}^{m} \pi_{\mathbf{t}_{j}}^{*(i)}\left(\mathcal{A}_{j}\right)\right) \leq \prod_{j=1}^{m} \mu_{\beta, N}\left(\bigcap_{\mathbf{t} \in \widetilde{\mathbb{T}}_{N}^{(i)}} \pi_{\mathbf{t}}^{*(i)}\left(\mathcal{A}_{j}\right)\right)^{1 / / \widetilde{\mathbb{T}}_{N}^{(i)} \mid}
$$

O leitor interessado na prova pode ver, por exemplo, o Teorema 5.8 de [7] ou o Teorema $2.4 \mathrm{em}$ [8].

A moral desta desigualdade, se focarmos em (3.26), é que a probabilidade de qualquer número de $\Lambda$-eventos, pode ser limitada superiormente por um produto das probabilidades, do evento propagado a todos os blocos do toro $\mathbb{T}_{N}$. Isto é particularmente útil para estimar a probabilidade de ocorrência de contornos; é claro, desde que a palavra contorno refira-se a um conjunto de blocos em cada um dos quais algum evento ruim ocorre. Desta forma, a probabilidade de um contorno irá automaticamente ser suprimida de forma exponencial no número de blocos que constituem-se ruins.

Como veremos nos próximos capítulos, as seguintes quantidades desempenham um papel principal na prova da transição de fase. Seja

$$
\mathfrak{z}_{\beta, N}(\mathcal{A}):=\mu_{\beta, N}\left(\bigcap_{\mathbf{t} \in \widetilde{\mathbb{T}}_{N}} \pi_{\mathbf{t}}(\mathcal{A})\right)^{1 /\left|\widetilde{\mathbb{T}}_{N}\right|}
$$


onde $\mathcal{A}$ é um $\Lambda$-evento. De forma análoga, denotamos

$$
\mathfrak{z}_{\beta, N}^{(i)}:=\mu_{\beta, N}\left(\bigcap_{\mathbf{t} \in \widetilde{\mathbb{T}}_{N}} \pi_{\mathbf{t}}^{*(i)}(\mathcal{A})\right)^{1 /\left|\widetilde{\mathbb{T}}_{N}^{(i)}\right|},
$$

definida pelos $\Lambda^{*}$-eventos $\mathcal{A}$, em que $i=1,2$.

A função $\mathcal{A} \rightarrow \mathfrak{z}_{\beta, N}(\mathcal{A})$ é não-aditiva. No entanto, dado a $\sigma$-aditividade de $\mu$, e usando a estimativa de chessboard, é fácil provar que é subaditiva (ver [7], Lema 5.9). Isto é: para qualquer conjunto de $\Lambda$-eventos $\mathcal{A}, \mathcal{A}_{1}, \mathcal{A}_{2}, \ldots$, tais que $\mathcal{A} \subset \cup_{k} \mathcal{A}_{k}$, a desigualdade

$$
\mathfrak{z}_{\beta, N}(\mathcal{A}) \leq \sum_{k} \mathfrak{z}_{\beta, N}\left(\mathcal{A}_{k}\right)
$$

é valida.

As versões limite destas quantidades serão de particular interesse para nós. Assim, definimos

$$
\mathfrak{z} \beta(\mathcal{A}):=\lim _{N \rightarrow \infty} \mathfrak{z} \beta, N(\mathcal{A}),
$$

$\mathrm{e}$

$$
\mathfrak{z}_{\beta}^{(i)}(\mathcal{A}):=\lim _{N \rightarrow \infty} \mathfrak{z}_{\beta, N}^{(i)}(\mathcal{A}) .
$$

A existência dos limites segue a partir da subaditividade.

Na próxima seção, definimos um segundo método. Tal método será usado na prova da unicidade da medida de Gibbs, no modelo de Ising do tipo cell-board.

\subsection{O método de Disagreement Percolation}

Os trabalhos de van den Berg [5] e van den Berg e Maes [6], estudam a influência de uma condição de contorno sobre o estado de um campo de Markov (ver (2.11)), em termos de disagreement percolation. Isto, através da construção de um acoplamento entre duas realizações do campo de Markov sob diferentes condições de contorno. O efeito da condição de contorno é então estimado em termos de probabilidades do tipo percolação. O principal resultado é a formulação de várias propriedades do acoplamento. Isto permite derivar limitantes superiores para os efeitos das condições de contorno. Formalmente, um critério de unicidade de medidas de Gibbs foi obtido com este método.

Primeiramente, considere o grafo $\mathbb{G}$ em (3.1). Tal grafo é localmente finito (ou seja, cada vértice tem um número finito de arestas). Usamos a notação $v \sim w$ para indicar que dois vértices $v$ e $w$ são adjacentes ou vizinhos, o que significa que existe uma aresta entre eles. A vizinhança de um vértice $i$, é o conjunto de todos os $j \sim i$, denotada por $\mathcal{N}_{i}$. Por um caminho queremos dizer uma sequência (finita ou infinita) de distintos vértices $v_{1}, v_{2} \ldots$, em que os vértices consecutivos são adjacentes.

A seguir expomos algumas definições e resultados básicos sobre o modelo de percolação de sítios na rede quadrada. Também apresentamos a noção de distância variacional, usada na técnica de acoplamento de variáveis aleatórias. 


\section{Percolação de sítios em $\mathbb{Z}^{2}$.}

Suponha que cada vértice $i \in \mathbb{Z}^{2}$ seja, independente de todos os outros vértices, aberto (ou seja acessível) com probabilidade $p_{i}$, e fechado com probabilidade $1-p_{i}$. Denotamos a medida de probabilidade produto correspondente por $P_{\left\{p_{i}\right\}}$. Para a realização do processo, um caminho é chamado aberto se todos os seus vértices estão abertos.

Dizemos que percolação ocorre se

$$
P_{\left\{p_{i}\right\}} \text { ('existe um caminho aberto infinito') }>0,
$$

neste caso a probabilidade é igual a 1, uma vez que o evento é um evento caudal. No caso de todos os $p_{i}$ iguais, digamos $p$, escrevemos $P_{p}$ para a medida de probabilidade acima, e definimos a probabilidade crítica como

$$
p_{c}=\inf \left\{p \in[0,1]: P_{p}(\text { 'existe um caminho aberto infinito' })>0\right\} .
$$

Um dos primeiros problemas em percolação foi mostrar que $p_{c}<1$, para uma grande classe de grafos, incluindo a rede quadrada. Um fato importante para a técnica proposta por van den Berg [5], é a disponibilidade de limitantes inferiores para $p_{c}$. Sabe-se, de acordo com um primeiro resultado em teoria de percolação, que $p_{c}\left(\mathbb{Z}^{2}\right) \geq 1 / 2$. A desigualdade estrita foi provada por Higuchi [28], isto é

$$
p_{c}\left(\mathbb{Z}^{2}\right)>\frac{1}{2}
$$

é este o resultado que usaremos em nosso estudo.

O modelo acima é chamado de percolação independente (ou Bernoulli) de sítios. Se os estados não se comportam independentes um do outro, falamos de percolação dependente. Se as arestas

$e \in \mathbb{E}$, ao invés dos vértices estão abertas ou fechadas, falamos de percolação de elos em $\mathbb{Z}^{2}$. Para um estudo mais aprofundado, ver Grimmett [27] e Kesten [31].

\section{Acoplamento e distância variacional.}

A condição de unicidade obtida por van den Berg e Maes [6], foca-se em ferramentas sobre acomplamento. Estas podem ser encontradas na referência padrão, Lindvall [35].

Particularmente, precisamos definir a chamada distância variacional, para estimar a probabilidade de desacordo em um determinado sítio $i \in \mathbb{Z}^{2}$, das duas realizações com diferente condição de contorno.

De forma geral, seja $L$ um conjunto finito, e sejam $X_{1}$ e $X_{2}$ duas variáveis aleatórias $L$-valoradas com distribuição de probabilidade $\rho_{1}$ e $\rho_{2}$, respectivamente. A distância variacional de $X_{1}$ e $X_{2}$ (ou, equivalentemente, de $\rho_{1}$ e $\rho_{2}$ ) é definida por

$$
d\left(\rho_{1}, \rho_{2}\right)=\frac{1}{2} \sum_{a \in L}\left|\rho_{1}(a)-\rho_{2}(a)\right| .
$$


Uma definição equivalente é

$$
d\left(\rho_{1}, \rho_{2}\right)=\max _{E \subset L}\left|\rho_{1}(E)-\rho_{2}(E)\right| .
$$

A seguir, expomos um corolário do principal resultado apresentado em [6], este sobre o acoplamento de duas especificações com diferente condição de contorno. Isto é: $Y_{i}(\cdot, \eta)$ e $Y_{i}\left(\cdot, \eta^{\prime}\right), i \in \mathbb{Z}^{2}$, como definidas em (2.12).

\subsubsection{Critério de unicidade}

Considere a definição de especificação dada em (2.12). Assim, para cada $i \in \mathbb{Z}^{2}$, denotamos

$$
p_{i}=\max _{\eta, \eta^{\prime} \in S^{\mathcal{N}_{i}}} d\left(Y_{i}(\cdot, \eta), Y_{i}\left(\cdot, \eta^{\prime}\right)\right) .
$$

O seguinte enunciado representa o critério de unicidade obtido por van den Berg e Maes [6], o qual aprimora a condição de unicidade proposta no primeiro trabalho de van den Berg [5]. Este critério será usado nas próximas seções. Para interpretá-lo, devemos pensar que a ausência de percolação implica ausência de transição de fase.

Critério 3.2.1 (Ver Corolário 2 em [6]). Seja $P_{\left\{p_{i}\right\}}$ a medida produto do modelo de percolação de sítios acima definido, em que $p_{i}$ é dado por (3.36). Se

$$
P_{\left\{p_{i}\right\}} \text { ('existe um caminho aberto infinito') }=0,
$$

então a especificação Y possui no máximo uma medida de Gibbs. Particularmente, isto acontece se

$$
\sup _{i \in \mathbb{Z}^{2}} p_{i}<p_{c}\left(\mathbb{Z}^{2}\right)
$$

Concluindo este capítulo, resumimos as principais ferramentas a serem utilizadas no Capítulo 5 . Por um lado, o Teorema 3.1.1, que permite construir um argumento de contornos similar às ideias de Peierls, para provar transição de fase. Por outro lado, o Critério 3.2.1, o qual fornece uma região de unicidade para o modelo em estudo. 


\section{Capítulo 4}

\section{Resultados Principais}

Este capítulo inclui os principais resultados do nosso trabalho. Em primeiro lugar, obtemos uma região de unicidade da medida de Gibbs, utilizando um critério de unicidade baseado na técnica de disagreement percolation.

O principal resultado da tese é o Teorema 4.2.1, o qual prova a existência de transição de fase no modelo de Ising do tipo cell-board, este resultado segue da propriedade de reflection positivity. Além disso, a transição de fase no modelo de Ising antiferromagnético com campo externo constante é provada como corolário do Teorema 4.2.1.

Finalmente, inclui-se uma versão do modelo estudado em Nardi et al. [37]. Isto é, um campo externo de faixas alternadas, provando transição de fase com uma metodologia similar à do resultado principal.

\subsection{Unicidade da medida de Gibbs}

Como definimos anteriormente, a unicidade de fase é dada pela existência de uma única medida de Gibbs. Isto é, $\left|\mathcal{G}_{\beta}\right|=1$. Sabemos do trabalho de Nardi et al. [37], que uma técnica adequada a ser utilizada é a de cluster expansion. Porém, no trabalho citado foi preciso usar muitas definições e construções que tornam a prova bastante complicada. Desta forma, propomos um método mais probabilístico para abordar este problema. A prova do nosso resultado consiste em verificar a condição de unicidade dada no Critério 3.2.1.

Nossa região de unicidade completa o diagrama de fases do modelo de Ising do tipo cell-board, somente no caso de $L_{1}=L_{2}=1$. Portanto, em pesquisas futuras esperamos obter regiões mais aprimoradas, usando técnicas como cluster expansion ou as ferramentas da teoria de Pirogov-Sinai.

\subsubsection{Teorema de unicidade para $h>4 J$}

A seguir, apresentamos o nosso principal resultado sobre unicidade da medida de Gibbs para os modelos de Ising do tipo cell-board. 
Teorema 4.1.1. Para

$$
\beta(4 J-h)<0
$$

o modelo de Ising do tipo cell-board em $\mathbb{Z}^{2}$ (definido por (2.3) e (2.4)), possui uma única medida de Gibbs.

\subsection{Transição de fase}

O nosso teorema principal provê a presença de uma transição de fase de primeira ordem no modelo de Ising do tipo cell-board. O modelo apresenta uma série de simetrias por reflexão, as quais são suficientes para aplicar a técnica de reflection positivity.

As reflexões são com respeito às linhas paralelas aos eixos de coordenadas. Como visto na Figura 3.2, o conjunto de linhas de reflexão fornece uma decomposição do toro $\mathbb{T}_{N}$ em blocos retangulares. Lembre que a soma total do campo externo em cada bloco é igual a zero. Dependendo da paridade do tamanho das células, definindo o sinal do campo externo, as retas de reflexão podem ir sobre os sítios de $\mathbb{Z}^{2}$ ou bissectar arestas de $\mathbb{E}$ (como definido em (3.1)).

Como corolário do nosso principal resultado, obtemos a transição de fase para o modelo de Ising antiferromagnético com campo externo constante. Este resultado foi inicialmente provado por Dobrushin [14]. Um estudo completo do modelo pode-se encontrar em Dobrushin et al. [15].

Outro resultado sobre transição de fase é apresentado no Teorema 4.2.3. Consideramos um modelo que generaliza o campo externo proposto por Nardi, Olivieri e Zahradník [37]. O nosso campo externo é composto por faixas horizontais de altura $L$, onde o sinal do campo é alternado em tais faixas.

\subsubsection{Teorema de transição de fase para $h<2 J / L_{1}+2 J / L_{2}$}

A seguir, apresentamos o principal resultado deste trabalho. No seguinte teorema obtemos transição de fase na região de coexistência (2.8). Incluímos também uma estimativa da temperatura crítica.

Teorema 4.2.1. Suponha que a condição (2.8) seja valida, então existe $\beta_{c}=\beta_{c}\left(L_{1}, L_{2}\right)$, tal que para todo $\beta>\beta_{c}$, existem duas medidas distintas $\mu_{\beta}^{+}$e $\mu_{\beta}^{-} \in \mathcal{G}_{\beta}$, satisfazendo

$$
\mu_{\beta}^{ \pm}(\sigma(t)= \pm 1)>\frac{1}{2}
$$

Isto significa $\left|\mathcal{G}_{\beta}\right|>1$. Ademais

$$
\beta_{c} \leq \frac{2\left[\left(B_{1} B_{2}+4\right) \ln (2)+\ln (90)\right]}{2 J-\frac{h L_{1} L_{2}}{L_{1}+L_{2}}},
$$

$B_{i}$ definido em (3.13). 
Provando o nosso Teorema 4.2.1, estimamos a probabilidade de ter diferentes valores dos spins, isto é: +1 e -1 , em dois sítios remotos sobre o toro (ver Proposição 5.2.3). O seguinte passo é provar que a probabilidade deste evento é pequena. Note que o evento

$$
(\sigma(s)=+1, \sigma(t)=-1)
$$

quando $s \neq t$, deve gerar um contorno de Peierls $\gamma$, o qual é o conjunto de arestas em $\mathbb{E}$, possuindo diferente valor dos spins em seus extremos. Usamos os argumentos de contorno para a prova, mas precisamos definir e adaptar as ideias para o que chamamos de "contornos de blocos". O contorno de blocos é formado pelos blocos, definidos pelas retas de reflexão em (3.10), em que o contorno dual de Peierls $\gamma^{*}$ passa. No interior desse tipo de blocos, sempre teremos uma configuração não constante, uma configuração bloco-ruim. Existe um caso que precisa ser tratado de maneira diferente (ver bloco-duplo na seção 5). A probabilidade pequena das configurações nos blocos-ruins segue da estimativa de chessboard, Teorema 3.1.1, e da condição de Peierls, Lema 5.2.5. A estimativa de chessboard é aplicada para encontrar limites superiores para a probabilidade dos blocos-ruins. A condição de Peierls será aplicada para obter limitantes superiores pequenos a baixas temperaturas (ver Proposição 5.2.2).

\subsubsection{Corolário para o Ising antiferromagnético com campo externo uniforme}

Nesta seção, apresentamos a equivalência entre um caso particular do modelo de Ising do tipo cell-board e o modelo de Ising antiferromagnético com campo externo uniforme. Lembre que o Hamiltoniano formal nesse caso é dado por

$$
H_{a}(\sigma)=-J_{a} \sum_{\langle t, s\rangle} \sigma(t) \sigma(s)-h_{a} \sum_{s} \sigma(s)
$$

onde o parâmetro $J_{a}$ é negativo, $J_{a}<0$, definindo a interação antiferromagnética entre os sítios mais próximos, o campo externo $h_{a}$ é uma constante real.

Como indica a Observação 1, e que provaremos a seguir, o Hamiltoniano do Ising antiferromagnético com campo externo constante $h_{a}=h$, é equivalente ao modelo de Ising do tipo cell-board, $\pm h$, quando $L_{1}=L_{2}=1$.

Portanto, o resultado sobre transição de fase no modelo antiferromagnético com campo externo constante (ver por exemplo [15]), deve ser consequência da transição de fase do nosso modelo. De outra forma, o seguinte resultado deriva-se do Teorema 4.2.1.

Corolário 4.2.2. Sejam $J, h>0$. Se $h<4 J$ e $\beta>\frac{2 k}{4 J-h}$ para algum $k>0$, então o modelo de Ising antiferromagnético (4.4) com $J_{a}=-J$ e $h_{a}=h$, possui duas medidas de Gibbs. 
Demonstração. A transformação $\Psi$ do espaço de configurações $\Omega, \Psi: \Omega \rightarrow \Omega$,

$$
\Psi(\sigma)\left(t_{1}, t_{2}\right)= \begin{cases}\sigma\left(t_{1}, t_{2}\right), & \text { se } t_{1}+t_{2} \text { é par, } \\ -\sigma\left(t_{1}, t_{2}\right), & \text { caso contrário, }\end{cases}
$$

é uma transformação um-a-um de $\Omega$. Note que, se em (4.4) escolhemos $J_{a}=-J$, onde $J>0$, e $h_{a}=h$, então

$$
\begin{aligned}
H_{a}(\Psi(\sigma)) & =J \sum_{\langle t, s\rangle} \Psi(\sigma)(t) \Psi(\sigma)(s)-h \sum_{s} \Psi(\sigma)(s) \\
& =-J \sum_{\langle t, s\rangle} \sigma(t) \sigma(s)-\sum_{s} h(s) \sigma(s)=H(\sigma),
\end{aligned}
$$

em que

$$
h(t)= \begin{cases}h, & \text { se } t=\left(t_{1}, t_{2}\right), t_{1}+t_{2} \text { é par } \\ -h, & \text { caso contrário. }\end{cases}
$$

Isto significa que a transformação $\Psi$ não muda a energia entre as configurações, e entrega uma equivalência direta entre os dois modelos.

Finalmente, dado (4.3) e o fato que $L_{1}=L_{2}=1$, obtemos a estimativa desejada.

\subsubsection{Transição de fase para um campo externo de faixas alternadas}

A seguir, propomos uma classe de modelos baseada no modelo definido na Seção 2.1.2. Neste caso, definimos um campo externo com faixas horizontais infinitas, de altura $L$, nas quais colocamos um campo externo alternado. Salientamos que desta forma, obtemos uma classe de campos externos que inclui o modelo estudado por Nardi et al. [37], particularmente na linha de coexistência, $h_{1}=h_{2}<2 J$.

Formalmente, consideramos $L \in \mathbb{N}$. Assim, para cada inteiro $n$, definimos a faixa

$$
F(n)=\left\{\left(t_{1}, t_{2}\right) \in \mathbb{Z}^{2}: n L \leq t_{2}<(n+1) L\right\} .
$$

Note que $\mathbb{Z}^{2}=\cup_{n \in \mathbb{Z}} F(n)$. De forma semelhante a (2.2), pensamos as faixas sendo coloridas de cor branca ou preta. Ver Figura 5.4, onde $L=2$. Então, definimos os subconjuntos $\mathbf{Z}_{+}^{*}$ e $\mathbf{Z}_{-}^{*}$ de $\mathbb{Z}^{2}$.

$$
\mathbf{Z}_{+}^{*}=\bigcup_{\substack{n: \\ n \text { é par }}} F(n), \quad \mathbf{Z}_{-}^{*}=\mathbb{Z}^{2} \backslash \mathbf{Z}_{+}^{*} .
$$

Seja $\Omega=\{-1,+1\}^{\mathbb{Z}^{2}}$ o conjunto de configurações em $\mathbb{Z}^{2}$. O Hamiltoniano formal, para o modelo de Ising com faixas alternadas, é definido por (2.3), e o campo externo é dado por

$$
h(s)=\left\{\begin{aligned}
h, & \text { se } s \in \mathbf{Z}_{+}^{*}, \\
-h, & \text { se } s \in \mathbf{Z}_{-}^{*},
\end{aligned}\right.
$$


em que $h>0$. Observe que, para $L=1$, o campo externo coincide com o estudado por Nardi et al. [37].

Finalmente, apresentamos o resultado da transição de fase para este campo externo de faixas alternadas.

Teorema 4.2.3. Considere o modelo de Ising com faixas alternadas, definido pelo Hamiltoniano em (2.3), com campo externo dado por (4.5), (4.6) e (4.7). Se $h<2 J / L$, então existe uma constate positiva adequada $k=k(L)$, tal que para todo $\beta>k /(2 J-h L)$, existem duas medidas distintas $\mu_{\beta}^{+}$ e $\mu_{\beta}^{-} \in \mathcal{G}_{\beta}$, as quais satisfazem

$$
\begin{aligned}
& \mu_{\beta}^{+}(\sigma(t)=1)>\frac{1}{2}, e \\
& \mu_{\beta}^{-}(\sigma(t)=-1)>\frac{1}{2} .
\end{aligned}
$$

Como veremos no Capítulo 5, a demonstração deste teorema segue o roteiro do Teorema 4.2.1, mas a principal diferença é a caracterização dos estados fundamentais. Neste caso, é importante observar que em cada linha horizontal, o valor do campo externo é constante. Porém, as ideias usadas por Maruani et al. [36], permitem obter as estimativas necessárias quando $h<2 J / L$. 


\section{Capítulo 5}

\section{Demonstrações}

Apresentamos as provas dos principais resultados expostos no capítulo anterior. Primeiro, aplicase o critério de unicidade (Critério 3.2.1) para caracterizar a região de unicidade em $h>4 J$, como enunciado no Teorema 4.1.1.

A prova do Teorema 4.2.1 requer a obtenção de cotas superiores para os eventos chamados de blocos-ruins, isto permite construir um argumento de tipo Peierls, estimando a probabilidade dos contornos de blocos. Assim, como passo final precisamos construir duas medidas, $\mu_{\beta}^{+}$e $\mu_{\beta}^{-} \in \mathcal{G}_{\beta}$, as quais provamos ser diferentes.

Para provar o Teorema 4.2.3 seguimos um roteiro similar, as distinções são dadas pelo fato de ter em cada linha horizontal um campo externo constante. Porém, as ideias usadas por Maruani et al. [36], permitem obter um tipo de constante de Peierls.

\subsection{Prova do Teorema de unicidade}

Primeiro, dada a simplicidade da prova, apresentamos a demonstração do Teorema 4.1.1. Essencialmente, precisamos conferir a desigualdade (3.38), considerando a medida de Gibbs em (2.13), sob a condição (4.1).

Demonstração. Baseados no Critério 3.2.1, precisamos conferir para todo $\beta>0$ e $h>4 J$, a desigualdade

$$
\sup _{i \in \mathbb{Z}^{2}} p_{i}<\frac{1}{2}
$$

aqui temos usado a desigualdade (3.33). Sabemos que, para cada $i \in \mathbb{Z}^{2}$,

$$
p_{i}=\max _{\eta, \eta^{\prime} \in\{-1,+1\}^{\mathcal{N}_{i}}} d\left(Y_{i}(\cdot, \eta), Y_{i}\left(\cdot, \eta^{\prime}\right)\right),
$$

em que a especificação $Y$ é definida pela medida de Gibbs (2.13). Para calcular $p_{i}$, denotamos $n=\sum_{j \in \mathcal{N}_{i}} \eta(j)$, e $n^{\prime}=\sum_{j \in \mathcal{N}_{i}} \eta^{\prime}(j)$. Assim, para cada $i \in \mathbb{Z}^{2}, Y_{i}(-1, \eta)+Y_{i}(+1, \eta)=1$, em que 


$$
Y_{i}(+1, \eta)=\frac{\exp (\beta J n+\beta h(i))}{\exp (-\beta J n-\beta h(i))+\exp (\beta J n+\beta h(i))}
$$

De forma análoga, para $Y_{i}\left(\cdot, \eta^{\prime}\right)$ devemos substituir $n$ por $n^{\prime}$. Dizemos que $n, n^{\prime} \in \mathcal{M}$, em que $\mathcal{M}=\{-4,-2,0,+2,+4\}$. Portanto, a equação (5.2) pode ser re-escrita da seguinte maneira,

$$
p_{i}=\max _{n, n^{\prime} \in \mathcal{M}} \frac{\left|\sinh \left(\beta J\left(n-n^{\prime}\right)\right)\right|}{\cosh \left(\beta J\left(n+n^{\prime}\right)+2 \beta h(i)\right)+\cosh \left(\beta J\left(n-n^{\prime}\right)\right)} .
$$

Note que os $p_{i}, i \in \mathbb{Z}^{2}$, podem assumir dois valores, os que dependem de $h(i)=h$ ou $-h$. De outra forma, denotamos

$$
p_{i}= \begin{cases}p_{+}, & \text {se } i \in \mathbf{Z}_{+}, \\ p_{-}, & \text {se } i \in \mathbf{Z}_{-} .\end{cases}
$$

Agora, focamos no valor de $p_{+}$, mas o procedimento para estudar $p_{-}$, é análogo. Finalmente, iremos concluir que $p_{+}=p_{-}$.

A seguir, supomos $h>4 J$. Como primeira conclusão, vemos que

$$
\beta J\left(n+n^{\prime}\right)+2 \beta h>0,
$$

para todo $n, n^{\prime} \in \mathcal{M}$. Então, a função $\cosh \left(\beta J\left(n+n^{\prime}\right)+2 \beta h\right)$, no denominador de (5.4), é uma função estritamente crescente em $\left(n+n^{\prime}\right)$. Este fato é essencial no argumento a seguir.

Por outro lado,

$$
p_{+}<\max _{n, n^{\prime} \in \mathcal{M}} \frac{\left|\sinh \left(\beta J\left(n-n^{\prime}\right)\right)\right|}{\cosh \left(\beta J\left(n+n^{\prime}+8\right)\right)+\cosh \left(\beta J\left(n-n^{\prime}\right)\right)} .
$$

Desta forma, o problema agora é estudar o máximo em função de $\left(n-n^{\prime}\right)$ e $\left(n+n^{\prime}\right)$. Porém, dado que as funções $|\sinh (x)|$ e $\cosh (x)$ são pares, então o estudo é restrito aos valores de $\left|n-n^{\prime}\right|$. Também, é claro que o máximo não pode encontrar-se em $n=n^{\prime}$.

Note que, uma vez fixado $\left|n-n^{\prime}\right| \in \mathcal{M}^{*}=\{2,4,6,8\}$, e dada a desigualdade em (5.6), o valor do máximo é atingido para o menor valor possível de $\left(n+n^{\prime}\right)$. Uma análise numérica simples indica que o máximo é atingido quando

$$
\left|n-n^{\prime}\right|=n+n^{\prime}+8
$$

No caso de $p_{-}$, vemos que $\beta J\left(n+n^{\prime}\right)-2 \beta h<0$. Repetindo as conclusões acima, é fácil comprovar que $p_{+}=p_{-}$. 
Finalmente, de (5.7), e da conclusão (5.8), dizemos que

$$
p_{i}<\max _{m \in \mathcal{M}^{*}} \frac{1}{2} \tanh (\beta J m) .
$$

Portanto, dado $h>4 J$, então $\sup _{i} p_{i}<1 / 2$, para todo $\beta>0$.

\subsection{Prova da transição de fase no modelo de Ising do tipo cell-board}

A base da prova do Teorema 4.2.1 são as Proposição 5.2.1, Proposição 5.2.2 e Proposição 5.2.3, que iremos provar na subseção 5.2.1.

A principal técnica utilizada é a técnica de reflection positivity. Também, usamos o método proposto por Maruani et al. [36], para caracterizar os estados fundamentais.

A prova consiste essencialmente de duas etapas. Em primeiro lugar, o passo mais fácil, a Proposição 5.2.1, aplicamos um critério conhecido para estabelecer a propriedade de RP para o nosso modelo. Em segundo lugar, construímos duas medidas $\mu_{\beta}^{+}$e $\mu_{\beta}^{-} \in \mathcal{G}_{\beta}$, e provamos que as probabilidades $\mu_{\beta}^{+}(\sigma(0)=-1)$ e $\mu_{\beta}^{-}(\sigma(0)=+1)$, podem ser feitas menor que $1 / 2$, para $\beta$ grande. Este fato comprova que as duas medidas de Gibbs são distintas, portanto provamos a coexistência de fases. A fim de proporcionar estas desigualdades, usamos a estimativa de chessboard (3.26 e 3.27), para um tipo de argumento de Peierls avaliando as probabilidades dos chamados contornos de blocos. Estas ideias serão implementadas na prova da Proposição 5.2.3.

A técnica de contornos com a qual trabalhamos é baseada no uso de contornos de blocos, estos são formados por um grupo de blocos $\{\Lambda+\mathbf{t}\}$, onde $\mathbf{t} \in \widetilde{\mathbb{T}}_{N}$ (como definido em (3.11)), e um conjunto de blocos-duplos $\left\{\Lambda^{*}\right\}$ (ver (3.18) e (3.22)), compostos por dois blocos vizinhos. Iremos descrever todos os detalhes mais tarde.

Além disso, iremos precisar de alguns resultados preliminares sobre $\mathfrak{z}_{\beta, N}$ e $\mathfrak{z}_{\beta, N}^{(i)}, i=1,2$, definidos em (3.28) e (3.29), respectivamente.

A seguir, verificamos a propriedade de RP para as medidas no toro do modelo de Ising do tipo cell-board. Como temos dito, a prova desta proposição segue na Seção 5.2.1.

Proposição 5.2.1. Para todo $P \in \mathcal{P}$ (ver (3.10)), e todo $\beta \geq 0$, a medida de Gibbs $\mu_{\beta, N}$ (3.4) no toro $\mathbb{T}_{N}$, é positiva por reflexão $(R P)$ com respeito a $\theta_{P}$.

Dado que o modelo em estudo apresenta a propriedade de RP, podemos usar as estimativas de chessboard. Para aplicar a desigualdade de chessboard, definimos os eventos que chamamos de blocos ruins.

Definição 3. Sejam $\sigma_{\Lambda}^{+}$e $\sigma_{\Lambda}^{-}$, as configurações constantes em $\Lambda$ com todos os spins +1 e todos os spins -1 , respectivamente. Chamamos uma configuração $\sigma_{\Lambda} \in\{-1,+1\}^{\Lambda}$, uma configuração $\Lambda$-boa 
se $\sigma_{\Lambda} \in\left\{\sigma_{\Lambda}^{+}, \sigma_{\Lambda}^{-}\right\}$, e configuração $\Lambda$-ruim caso contrário. Dizemos que o bloco $\Lambda$, é um bloco $\sigma$-bom se a configuração $\sigma_{\Lambda}$ é $\Lambda$-boa, caso contrário, o bloco $\Lambda$ é um bloco $\sigma$-ruim.

Nestas definições, o bloco $\Lambda$ pode ser substituído por qualquer bloco $\Lambda+\mathbf{t}, \mathbf{t} \in \widetilde{\mathbb{T}}_{N}$ com as correspondentes alterações dos termos.

Para cada configuração em $\Lambda, \sigma_{\Lambda} \in\{-1,+1\}^{\Lambda}$, definimos o evento

$$
\mathcal{B}\left(\sigma_{\Lambda}\right)=\left\{\sigma \in \Omega_{N}: \sigma(\Lambda)=\sigma_{\Lambda}\right\}
$$

isto é, o conjunto das configurações no toro $\mathbb{T}_{N}$, para as quais fixamos os spins no bloco $\Lambda$.

Seja $R(\Lambda)$ o conjunto de todas as configurações $\Lambda$-ruim, $R(\Lambda)=\{-1,+1\}^{\Lambda} \backslash\left\{\sigma_{\Lambda}^{+}, \sigma_{\Lambda}^{-}\right\}$. Lembrar que o tamanho do bloco $\Lambda$ é igual a $B_{1} B_{2}$ sítios, e $B_{i} \geq 2$ como definido em (3.13). Isto implica que $R(\Lambda)$ é não vazio, mais do que isso, $|R(\Lambda)|=2^{B_{1} B_{2}}-2 \geq 14$.

Denote $\mathcal{R}_{\Lambda}$, o evento em que o bloco $\Lambda$ é $\sigma$-ruim, para $\sigma \in \Omega_{N}$,

$$
\mathcal{R}_{\Lambda}=\bigcup_{\sigma_{\Lambda} \in R(\Lambda)} \mathcal{B}\left(\sigma_{\Lambda}\right)
$$

O evento $\mathcal{R}_{\Lambda}$, é chamado "evento bloco-ruim".

A prova do teorema principal sobre a coexistência de fases, baseia-se na técnica de contornos acima mencionada. Considerando um contorno usual de Peierls, iremos definir o contorno de blocos associado. Os contornos de blocos são compostos por $\Lambda$-blocos e $\Lambda^{*}$-blocos (ver (3.11), (3.18) e (3.22)). O $\Lambda$-bloco é incluido a um contorno de blocos, se o contorno de Peierls toca dito $\Lambda$-bloco. O $\Lambda^{*}$-bloco aparece no contorno de blocos quando o contorno de Peierls passa, pelo menos parcialmente, entre dois $\Lambda$-blocos vizinhos. Isto acontece quando o tamanho $L_{i}$ na direção das localizações do bloco é par.

Particularmente, quando $L_{1}$ (ou $\left.L_{2}\right)$ é par, se $\mathbf{t} \in\left\{\left(L_{1}, 0\right),\left(0, L_{2}\right)\right\}$, então os $\Lambda$-blocos vizinhos, $\Lambda$ e $\Lambda+\mathbf{t}$ não tem interseção, isto é $\Lambda \cap\left(\Lambda+\left(L_{1}, 0\right)\right)=\emptyset\left(\right.$ ou $\left.\Lambda \cap\left(\Lambda+\left(0, L_{2}\right)\right)=\emptyset\right)$.

A seguir, para precisar estas ideias, definimos o chamado "evento bloco-duplo-ruim". Se $\sigma_{\Lambda^{*}}$, é uma configuração no bloco-duplo $\Lambda^{*}$, então

$$
\mathcal{B}\left(\sigma_{\Lambda^{*}}\right)=\left\{\sigma \in \Omega_{N}: \sigma\left(\Lambda^{*}\right)=\sigma_{\Lambda^{*}}\right\}
$$

Usamos a Definição 3 para os blocos-duplos $\Lambda^{*}$, substituindo $\Lambda$ por $\Lambda^{*}$. Como em (5.11), definimos

$$
\mathcal{R}_{\Lambda^{*}}=\bigcup_{\sigma_{\Lambda^{*}} \in R\left(\Lambda^{*}\right)} \mathcal{B}\left(\sigma_{\Lambda^{*}}\right)
$$

Nosso foco está em configurações $\sigma \in \Omega_{N}$, sendo $\Lambda^{*}$-ruim tal que se $L_{1}$ é par, então

$$
\sigma\left(\frac{L_{1}}{2}-1, t_{2}\right) \neq \sigma\left(\frac{L_{1}}{2}, t_{2}\right)
$$


em que $t_{2} \in\left\{\left[-\frac{L_{2}+1}{2}, \frac{L_{2}-1}{2}\right] \cap \mathbb{T}_{N}\right\}$, e se $L_{2}$ é par, então

$$
\sigma\left(t_{1}, \frac{L_{2}}{2}-1\right) \neq \sigma\left(t_{1}, \frac{L_{2}}{2}\right)
$$

onde $t_{1} \in\left\{\left[-\frac{L_{1}+1}{2}, \frac{L_{1}-1}{2}\right] \cap \mathbb{T}_{N}\right\}$. As propriedades (5.14) e (5.15), são tais que os valores dos spins $\sigma$, são diferentes na linha fronteira de ambos os blocos constituindo o bloco-duplo $\Lambda^{*}$, o qual claramente será $\sigma$-ruim.

Denote $\mathcal{R}_{\Lambda^{*}}^{b} \subset \mathcal{R}_{\Lambda^{*}}$, sendo o evento $\Lambda^{*}$-ruim, ou bloco-duplo-ruim, tal que todas as configurações de $\mathcal{R}_{\Lambda^{*}}^{b}$, satisfazem (5.14) ou (5.15).

Na seguinte proposição mostramos que os eventos $\Lambda$-ruim e $\Lambda^{*}$-ruim, tem probabilidade pequena quando $\beta$ é suficientemente grande, isto independente de $N$ (ver definições (3.28) e (3.29)).

Proposição 5.2.2. Se a condição (2.8) é valida, então para toda configuração $\Lambda$-bloco, $\sigma_{\Lambda} \in R(\Lambda)$, a desigualdade

$$
\mathfrak{z}_{\beta, N}\left(\mathcal{B}\left(\sigma_{\Lambda}\right)\right) \leq \exp \left\{-\beta\left(2 J-\frac{h L_{1} L_{2}}{L_{1}+L_{2}}\right)\right\}
$$

vale para todo $N$ par. Assim,

$$
\mathfrak{z}_{\beta, N}\left(\mathcal{R}_{\Lambda}\right) \leq 2^{B_{1} B_{2}} \exp \left\{-\beta\left(2 J-\frac{h L_{1} L_{2}}{L_{1}+L_{2}}\right)\right\}
$$

Além disso, para cada configuração $\sigma_{\Lambda^{*}} \in R\left(\Lambda^{*}\right)$, a desigualdade similar

$$
\mathfrak{z}_{\beta, N}^{(i)}\left(\mathcal{B}\left(\sigma_{\Lambda^{*}}\right)\right) \leq \exp \left\{-\beta\left(2 J-\frac{h L_{1} L_{2}}{L_{1}+L_{2}}\right)\right\}
$$

vale para $i=1,2$, e todo $N$ múltiplo de 4. Ademais

$$
\mathfrak{z}_{\beta, N}^{(i)}\left(\mathcal{R}_{\Lambda^{*}}\right) \leq 4^{B_{1} B_{2}} \exp \left\{-\beta\left(2 J-\frac{h L_{1} L_{2}}{L_{1}+L_{2}}\right)\right\} .
$$

Observe que o valor dentro das chaves é a constante de Peierls definida no Teorema 2.1.1.

Portanto, agora podemos enunciar a proposição principal.

Proposição 5.2.3. Seja a condição (2.8) verdadeira. Existe uma constante $c>1$, tal que para todo $s, t \in \mathbb{T}_{N}$, a seguinte desigualdade

$$
\mu_{\beta, N}(\sigma(s)=+1, \sigma(t)=-1) \leq 2 c(c+1) 2^{B_{1} B_{2}} \exp \left\{-\frac{\beta}{2}\left(2 J-\frac{h L_{1} L_{2}}{L_{1}+L_{2}}\right)\right\},
$$

vale para todo

$$
\beta>\beta^{\prime}=\frac{2\left[\left(B_{1} B_{2}+1\right) \ln (2)+\ln (c(c+1))\right]}{2 J-\frac{h L_{1} L_{2}}{L_{1}+L_{2}}} .
$$


A constante $c$, aparece a partir do argumento combinatório relacionado com o número de contornos de blocos construídos a partir de um total de $n$ blocos, sejam simples $\Lambda$ ou duplos $\Lambda^{*}$.

\section{Prova do Teorema 4.2.1.}

Primeiro que tudo, usamos a seguinte simetria da medida de Gibbs (3.4) no toro. Seja $\Lambda_{s}$, o bloco contendo o sítio $s \in \mathbb{T}_{N}$, então

$$
\mu_{\beta, N}\left(\sigma: \sigma\left(\Lambda_{s}\right) \equiv+1\right)=\mu_{\beta, N}\left(\sigma: \sigma\left(\Lambda_{s}\right) \equiv-1\right)=\frac{1-\mu_{\beta, N}\left(\mathcal{R}\left(\Lambda_{s}\right)\right)}{2}
$$

para todo $s \in \mathbb{T}_{N}$, em que $\mathcal{R}\left(\Lambda_{s}\right)$ como definido em (5.11). Conferimos esta simetria para alguma configuração $\sigma \in \Omega_{N}$, tal que $\sigma(\Lambda) \equiv+1$. Assim, consideramos as seguintes duas transformações. Primeiro, aplicamos sobre $\sigma$ o operador de reflexão $\theta_{Q_{i}}$, definido na Seção 3.1.1, em que $Q_{i}$ é dado pela equação (3.15). Particularmente, escolhemos $Q_{1}$, isto é, $\omega:=\theta_{Q_{1}}(\sigma) \in \Omega_{N}$, assumindo valores $\omega\left(t_{1}, t_{2}\right)=\sigma\left(-t_{1}-1, t_{2}\right)$, para todo $t=\left(t_{1}, t_{2}\right) \in \mathbb{T}_{N}$. Como segundo passo, obtemos a configuração $\sigma^{\prime}=-\omega$, trocando o valor de todos os spins. Em outras palavras, $\sigma^{\prime}(t)=-\sigma\left(-t_{1}-1, t_{2}\right)$, para todo $t \in \mathbb{T}_{N}$. Claramente, $\sigma^{\prime}(\Lambda) \equiv-1$, e dado que $h_{\left(t_{1}, t_{2}\right)}=-h_{\left(-t_{1}-1, t_{2}\right)}$, os Hamiltonianos são equivalentes $H_{N}(\sigma)=H_{N}\left(\sigma^{\prime}\right)$.

Por outra parte, dada a propriedade de simetria do modelo, e a periodicidade do campo externo, as seguintes igualdades são validas

$$
\mu_{\beta, N}\left(\mathcal{R}_{\Lambda}\right)=\mu_{\beta, N}\left(\mathcal{R}_{\Lambda+\mathbf{t}}\right)
$$

para todo $\mathbf{t} \in \widetilde{\mathbb{T}}_{N}$. Por isso, às vezes omitimos o índice $\Lambda$ em $\mathcal{R}$.

Usando a estimativa de chessboard (3.26), obtemos a desigualdade

$$
\mu_{\beta, N}(\mathcal{R}) \leq \mu_{\beta, N}\left(\bigcap_{\mathbf{t} \in \widetilde{\mathbb{T}}_{N}} \pi_{\mathbf{t}}(\mathcal{R})\right)^{1 /\left|\widetilde{\mathbb{T}}_{N}\right|}=\mathfrak{z}_{\beta, N}(\mathcal{R}) .
$$

Então, a partir de (5.22)

$$
\mu_{\beta, N}\left(\sigma: \sigma\left(\Lambda_{s}\right) \equiv+1\right) \geq \frac{1-\mathfrak{z}_{\beta, N}(\mathcal{R})}{2}
$$

Neste momento, iremos construir duas medidas de Gibbs. Seja $t \in \mathbb{T}_{N}$, tal que $t=s+\left(N L_{1} / 2,0\right)$, defina

$$
\mu_{\beta, N}^{ \pm}(\cdot):=\mu_{\beta, N}(\cdot \mid \sigma(t)= \pm 1) .
$$

Por (5.24), (5.17), e a Proposição 5.2.3, temos que

$$
\begin{aligned}
\mu_{\beta, N}^{+}(\sigma(s)=-1) & \leq \frac{\mu_{\beta, N}(\sigma(s)=-1, \sigma(t)=+1)}{\mu_{\beta, N}\left(\sigma: \sigma\left(\Lambda_{t}\right) \equiv+1\right)} \\
& \leq \frac{4 c(c+1) 2^{B_{1} B_{2}} \exp \left\{-\frac{\beta}{2}\left(2 J-h \frac{L_{1} L_{2}}{L_{1}+L_{2}}\right)\right\}}{1-2^{B_{1} B_{2}} \exp \left\{-\beta\left(2 J-h \frac{L_{1} L_{2}}{L_{1}+L_{2}}\right)\right\}},
\end{aligned}
$$


$\mathrm{e}$

$$
\mu_{\beta, N}^{-}(\sigma(s)=+1) \leq \frac{4 c(c+1) 2^{B_{1} B_{2}} \exp \left\{-\frac{\beta}{2}\left(2 J-h \frac{L_{1} L_{2}}{L_{1}+L_{2}}\right)\right\}}{1-2^{B_{1} B_{2}} \exp \left\{-\beta\left(2 J-h \frac{L_{1} L_{2}}{L_{1}+L_{2}}\right)\right\}} .
$$

Quando $N \nearrow \infty$, extraímos a partir das sequências das medidas $\left(\mu_{\beta, N}^{+}\right)$e $\left(\mu_{\beta, N}^{-}\right)$, duas subsequências convergentes. Seja $\mu_{\beta}^{+}$e $\mu_{\beta}^{-}$, sendo os correspondentes limites. Essas medidas são medidas de Gibbs a volume infinito, correspondentes ao Hamiltoniano $H((2.3)$ e (2.4)). Essas medidas são Gibbsianas como resultado da equação DLR (para detalhes, ver [7]).

Por (5.26) e (5.27), as desigualdades (4.2) são satisfeitas se

$$
16 c(c+1) 2^{B_{1} B_{2}} \exp \left\{-\frac{\beta}{2}\left(2 J-h \frac{L_{1} L_{2}}{L_{1}+L_{2}}\right)\right\}<1 .
$$

Esta desigualdade significa que, o inverso da temperatura crítica satisfaz

$$
\beta_{c} \leq \frac{2\left[\left(B_{1} B_{2}+4\right) \ln (2)+\ln (c(c+1))\right]}{2 J-\frac{h L_{1} L_{2}}{L_{1}+L_{2}}} .
$$

A constante $c$, será estimada posteriormente no Lema 5.2.6.

\subsubsection{Provas dos resultados auxiliares}

\section{Prova da Proposição 5.2.1.}

A prova é simplesmente uma aplicação dos critérios conhecidos para que uma medida seja positiva por reflexão. Fixe uma linha de reflexão $P \in \mathcal{P}$, e seja $\theta_{P}$ o operador reflexão correspondente. Os critérios aplicados ao nosso caso, afirmam que a medida $\mu_{\beta, N}$ é positiva por reflexão, se o seu Hamiltoniano pode ser representado na forma

$$
-H_{N}=A+\theta_{P}(A)+\sum_{\alpha} C_{\alpha} \theta_{P}\left(C_{\alpha}\right)
$$

onde $A, C_{\alpha}$, são funções $\mathcal{F}_{P}^{l}$-mensurável. Então, para todo $\beta \geq 0$, a medida de Gibbs no toro $\mu_{\beta, N}$, é RP com respeito a $\theta_{P}$ (ver Definição 2). O critério pode ser encontrado por exemplo, no Teorema 2.1 de Shlosman [45], ou Corolario 5.4 de Biskup [7].

No nosso caso, há duas possibilidades de $P \in \mathcal{P}: P$ passando pelos sítios de $\mathbb{T}_{N}$, ou não. No caso de $P$ passando através dos sítios de $\mathbb{T}_{N}$, escolha

$$
A=J \sum_{\substack{\langle t, s\rangle: \\ t \in \mathbb{T}_{N}^{l}, s \in \mathbb{T}_{N}^{l} \backslash P}} \sigma(t) \sigma(s)+\frac{J}{2} \sum_{\langle t, s\rangle \in P} \sigma(t) \sigma(s)+\sum_{s \in \mathbb{T}_{N}^{l} \backslash P} h(s) \sigma(s)+\frac{1}{2} \sum_{s \in P} h(s) \sigma(s),
$$


então, dado que $h(s)=h\left(\vartheta_{P}(s)\right)$,

$$
-H_{N}(\sigma)=A+\theta_{P}(A)
$$

aqui as funções $C_{\alpha} \equiv 0$. No caso de reflexões através das arestas, escolher

$$
A=J \sum_{\langle t, s\rangle \in \mathbb{T}_{N}^{l}} \sigma(t) \sigma(s)+\sum_{s \in \mathbb{T}_{N}^{l}} h(s) \sigma(s)
$$

então

$$
-H_{N}(\sigma)=A+\theta_{P}(A)+J \sum_{\substack{t \in \mathbb{T}_{N}^{l}: \\|t-P|=1 / 2}} \sigma(t) \theta_{P}(\sigma(t)) .
$$

A igualdade $h(s)=h\left(\vartheta_{P}(s)\right)$, é usada novamente. Isso prova a proposição.

\section{Prova da Proposição 5.2.2.}

Seja $\sigma_{\Lambda, N}:=\cap_{\mathbf{t} \in \widetilde{\mathbb{T}}_{N}} \pi_{\mathbf{t}}\left(\mathcal{B}\left(\sigma_{\Lambda}\right)\right)$, a configuração em $\mathbb{T}_{N}$, obtida pela propagação de uma configuração $\sigma_{\Lambda}$, fixada no bloco $\Lambda$. A prova da Proposição 5.2.2, será baseada na seguinte desigualdade

$$
\mathfrak{z}_{\beta, N}\left(\mathcal{B}\left(\sigma_{\Lambda}\right)\right)^{\left|\widetilde{\mathbb{T}}_{N}\right|}=\frac{\exp \left(-\beta H_{N}\left(\sigma_{\Lambda, N}\right)\right)}{Z_{N}(\beta)} \leq \exp \left(-\beta\left[H_{N}\left(\sigma_{\Lambda, N}\right)-H_{N}\left(\sigma^{+}\right)\right]\right) .
$$

Um limitante para o lado direito de (5.31), pode ser encontrado a partir dos próximos dois lemas.

Para formular o primeiro lema apresentamos algumas noções. Considere a configuração $\sigma_{\Lambda, N}$, introduzida acima. Para qualquer $\sigma_{\Lambda}$, a configuração $\sigma_{\Lambda, N}$, tem a seguinte propriedade de periodicidade: para qualquer $t \in \mathbb{T}_{N}$, e $\mathbf{t} \in \widetilde{\mathbb{T}}_{N}$, temos

$$
\sigma_{\Lambda, N}(t)=\sigma_{\Lambda, N}(t+2 \mathbf{t})
$$

Isto significa, que existe algum subreticulado minimal $\Lambda^{[2 \times 2]}$ de $\mathbb{T}_{N}$, tal que a configuração $\sigma_{\Lambda, N}$, pode ser obtida por translações de $\sigma_{\Lambda, N}\left(\Lambda^{[2 \times 2]}\right)$. De fato, usando o retângulo $\widehat{\Lambda}$, definido por (3.12), vamos definir

$$
\begin{aligned}
& \widehat{\Lambda}^{[2 \times 2]}:=\widehat{\Lambda} \cup\left(\widehat{\Lambda}+\left(0, L_{2}\right)\right) \cup\left(\widehat{\Lambda}+\left(L_{1}, 0\right)\right) \cup\left(\widehat{\Lambda}+\left(L_{1}, L_{2}\right)\right)+\left(\frac{1}{4}, \frac{1}{4}\right), \\
& \Lambda^{[2 \times 2]}:=\mathbb{T}_{N} \cap \widehat{\Lambda}^{[2 \times 2]} .
\end{aligned}
$$

Ver Figura 5.1 para ilustração.

Observe que $\left(\Lambda^{[2 \times 2]}+2 \mathbf{t}_{1}\right) \cap\left(\Lambda^{[2 \times 2]}+2 \mathbf{t}_{2}\right)=\emptyset$, se $\mathbf{t}_{1} \neq \mathbf{t}_{2}$, com $\mathbf{t}_{1}, \mathbf{t}_{2} \in \widetilde{\mathbb{T}}_{N}$. Para todo $\mathbf{t} \in \widetilde{\mathbb{T}}_{N}$, temos que $h(s)=h(s+2 \mathbf{t})$, bem como,

$$
\sigma_{\Lambda, N}\left(\Lambda^{[2 \times 2]}\right)=\sigma_{\Lambda, N}\left(\Lambda^{[2 \times 2]}+2 \mathbf{t}\right), \text { e } \mathbb{T}_{N}=\bigcup_{\mathbf{t} \in \widetilde{\mathbb{T}}_{N}}\left(\Lambda^{[2 \times 2]}+2 \mathbf{t}\right)
$$




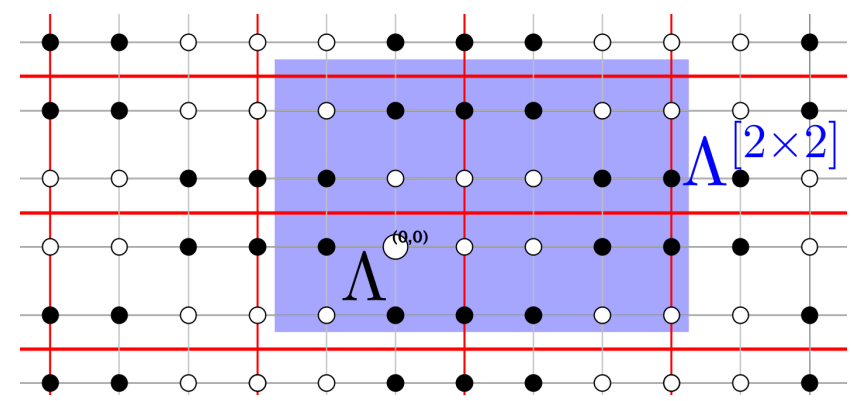

Figura 5.1: A subrede $\Lambda^{[2 \times 2]}$ é composta pelos sítios dentro do retângulo azul $\widehat{\Lambda}^{[2 \times 2]}$. Aqui $L_{1}=3$, e $L_{2}=2$.

Considere $\widetilde{\mathbb{T}}_{N}^{[2 \times 2]}=\left\{\mathbf{t}=\left(t_{1}, t_{2}\right) \in \mathbb{T}_{N}: t_{1}=2 n L_{1}, t_{2}=2 m L_{2}, n, m \in \mathbb{Z}\right\}$, e $\mathbb{T}^{[2 \times 2]}=\mathbb{T}_{N} / \widetilde{\mathbb{T}}_{N}^{[2 \times 2]}$. Vamos definir o Hamiltoniano no toro $\mathbb{T}^{[2 \times 2]}$ : para qualquer $\sigma \in\{-1,+1\}^{\mathbb{T}^{[2 \times 2]}}$, temos

$$
H_{[2 \times 2]}(\sigma)=-J \sum_{\langle t, s\rangle \in \mathbb{T}^{[2 \times 2]}} \sigma(t) \sigma(s)-\sum_{s \in \mathbb{T}^{[2 \times 2]}} h(s) \sigma(s) .
$$

Os sítios $\left(-\left\lfloor\frac{2 L_{1}+1}{4}\right\rfloor, t_{2}\right)^{1}$ e $\left(\left\lfloor\frac{3 L_{1}-1}{2}\right\rfloor, t_{2}\right) \in \Lambda^{[2 \times 2]}$, são vizinhos em $\mathbb{T}^{[2 \times 2]}$, para todo $t_{2} \in$ $\left[-\left\lfloor\frac{2 L_{2}+1}{4}\right\rfloor,\left\lfloor\frac{3 L_{2}-1}{2}\right\rfloor\right]$. Assim como $\left(t_{1},-\left\lfloor\frac{2 L_{2}+1}{4}\right\rfloor\right)$ e $\left(t_{1},\left\lfloor\frac{3 L_{2}-1}{2}\right\rfloor\right) \in \Lambda^{[2 \times 2]}$, serão vizinhos quando $t_{1} \in\left[-\left\lfloor\frac{2 L_{1}+1}{4}\right\rfloor,\left\lfloor\frac{3 L_{1}-1}{2}\right\rfloor\right]$.

Denote

$$
\sigma_{\Lambda,[2 \times 2]}:=\sigma_{\Lambda, N}\left(\Lambda^{[2 \times 2]}\right)
$$

A seguir, descreve-se a construção semelhante para os blocos-duplos. Desta forma, descrevemos os detalhes para o caso em que $L_{1}$ é par. Em seguida, o bloco duplo é $\Lambda_{1}^{*}$ (ver (3.24).) Para obter a propriedade que é análoga à (5.34), introduzimos os conjuntos

$$
\begin{aligned}
& \widehat{\Lambda}^{[4 \times 2](1)}=\widehat{\Lambda}_{1}^{*} \cup\left(\widehat{\Lambda}_{1}^{*}+\left(2 L_{1}, 0\right)\right) \cup\left(\widehat{\Lambda}_{1}^{*}+\left(0, L_{2}\right)\right) \cup\left(\widehat{\Lambda}_{1}^{*}+\left(2 L_{1}, L_{2}\right)\right)+\left(\frac{1}{4}, \frac{1}{4}\right), \\
& \Lambda^{[4 \times 2](1)}=\widehat{\Lambda}^{[4 \times 2](1)} \cap \mathbb{T}_{N} .
\end{aligned}
$$

O subgrupo correspondente é

$$
\widetilde{\mathbb{T}}_{N}^{[4 \times 2](1)}=\left\{\mathbf{t}=\left(t_{1}, t_{2}\right) \in \mathbb{T}_{N}: t_{1}=4 n L_{1}, t_{2}=2 m L_{2}, n, m \in \mathbb{Z}\right\},
$$

e o grupo quociente é

$$
\mathbb{T}^{[4 \times 2](1)}=\mathbb{T}_{N} / \widetilde{\mathbb{T}}_{N}^{[4 \times 2](1)} .
$$

O Hamiltoniano para $\sigma \in\{-1,+1\}^{\mathbb{T}^{[4 \times 2](1)}}$, é

$$
H_{[4 \times 2](1)}(\sigma)=-J \sum_{\langle t, s\rangle \in \mathbb{T}^{[4 \times 2](1)}} \sigma(t) \sigma(s)-\sum_{s \in \mathbb{T}^{[4 \times 2](1)}} h(s) \sigma(s) .
$$

\footnotetext{
${ }^{1}$ em que $\lfloor x\rfloor$, denota a função piso. Isto é: $\lfloor x\rfloor=\max \{m \in \mathbb{Z} \mid m \leq x\}$.
} 
Fixando alguma configuração $\sigma_{\Lambda_{1}^{*}}$, em $\Lambda_{1}^{*}$, obtemos a sua propagação como

$$
\sigma_{1, N}=\bigcap_{\mathbf{t} \in \widetilde{\mathbb{T}}_{N}^{[4 \times 2](1)}} \pi_{\mathbf{t}}\left(\mathcal{B}\left(\sigma_{\Lambda_{1}^{*}}\right)\right)
$$

e sua restrição sobre $\mathbb{T}^{[4 \times 2](1)}$ é

$$
\sigma_{1,[4 \times 2]}=\sigma_{1, N}\left(\Lambda^{[4 \times 2](1)}\right)
$$

$(\operatorname{ver}(5.12)$ e $(5.36))$.

Quando $L_{2}$ é par, obtemos as noções semelhantes: $\widehat{\Lambda}^{[4 \times 2](2)}, \Lambda^{[4 \times 2](2)}, \widetilde{T}_{N}^{[4 \times 2](2)}, \mathbb{T}^{[4 \times 2](2)}, \sigma_{2, N}, \sigma_{2,[4 \times 2]}$ e o Hamiltoniano $H_{[4 \times 2](2)}$.

Lema 5.2.4. Para cada configuração $\sigma_{\Lambda} \in\{-1,+1\}^{\Lambda}$,

$$
H_{N}\left(\sigma_{\Lambda, N}\right)=\left(\frac{N}{2}\right)^{2} H_{[2 \times 2]}\left(\sigma_{\Lambda,[2 \times 2]}\right)
$$

Se $N$ é múltiplo de 4 , então para $\sigma_{i,[4 \times 2]}$,

$$
H_{N}\left(\sigma_{i, N}\right)=\frac{N^{2}}{8} H_{[4 \times 2](i)}\left(\sigma_{i,[4 \times 2]}\right), i=1,2 .
$$

Demonstração. Note que o número de sítios em $\widetilde{\mathbb{T}}_{N}^{[2 \times 2]}$, é igual a $(N / 2)^{2}$. Portanto, para o termo que inclui o campo externo no Hamiltoniano, temos

$$
\sum_{s \in \mathbb{T}_{N}} h(s) \sigma_{\Lambda, N}(s)=\sum_{\mathbf{t} \in \widetilde{\mathbb{T}}_{N}^{[2 \times 2]}}\left(\sum_{s \in \Lambda^{[2 \times 2]}+\mathbf{t}} h(s) \sigma_{\Lambda, N}(s)\right)=\left(\frac{N}{2}\right)^{2} \sum_{s \in \mathbb{T}^{[2 \times 2]}} h(s) \sigma_{\Lambda,[2 \times 2]}(s) .
$$

Para o termo da interação entre vizinhos, em geral podemos escrever

$$
\begin{aligned}
& \sum_{\langle t, s\rangle \in \mathbb{T}_{N}} \sigma(t) \sigma(s)=\sum_{\mathbf{t} \in \widetilde{\mathbb{T}}_{N}^{[2 \times 2]}}\left(\sum_{\langle t, s\rangle \in \Lambda^{[2 \times 2]}+\mathbf{t}} \sigma(t) \sigma(s)+\right. \\
& \left.\sum_{\substack{\langle t, s\rangle: t \in\left(\Lambda^{[2 \times 2]}+\mathbf{t}\right), s \in\left(\Lambda^{[2 \times 2]}+\mathbf{t}+\left(2 L_{1}, 0\right)\right)}} \sigma(t) \sigma(s)+\sum_{\substack{\langle t, s\rangle: t \in\left(\Lambda^{[2 \times 2]}+\mathbf{t}\right), s \in\left(\Lambda^{[2 \times 2]}+\mathbf{t}+\left(0,2 L_{2}\right)\right)}} \sigma(t) \sigma(s)\right),
\end{aligned}
$$

para todo $\sigma \in \Omega_{N}$. Aplicamos essa representação para a configuração $\sigma_{\Lambda, N}$. Assim, lembrando a condição de periodicidade (5.34), obtemos

$$
\begin{aligned}
\sum_{\langle t, s\rangle \in \mathbb{T}_{N}} \sigma_{\Lambda, N}(t) \sigma_{\Lambda, N}(s) & =\sum_{\mathbf{t} \in \widetilde{\mathbb{T}}_{N}^{[2 \times 2]}} \sum_{\langle t, s\rangle \in \mathbb{T}^{[2 \times 2]}} \sigma_{\Lambda,[2 \times 2]}(t) \sigma_{\Lambda,[2 \times 2]}(s) \\
& =\left(\frac{N}{2}\right)^{2} \sum_{\langle t, s\rangle \in \mathbb{T}^{[2 \times 2]}} \sigma_{\Lambda,[2 \times 2]}(t) \sigma_{\Lambda,[2 \times 2]}(s) .
\end{aligned}
$$

A relação (5.43) segue de (5.45) e (5.47). 
A prova da igualdade (5.44) não difere das considerações anteriores, se substituímos $\sigma_{\Lambda, N}$ e $\sigma_{\Lambda,[2 \times 2]}$, por $\sigma_{i, N}$ e $\sigma_{i,[4 \times 2]}$, e os conjuntos $\widehat{\Lambda}^{[2 \times 2]}, \Lambda^{[2 \times 2]}, \widetilde{\mathbb{T}}_{N}^{[2 \times 2]}, \mathbb{T}^{[2 \times 2]}$ por $\widehat{\Lambda}^{[4 \times 2](i)}, \Lambda^{[4 \times 2](i)}, \widetilde{T}_{N}^{[4 \times 2](i)}, \mathbb{T}^{[4 \times 2](i)}$, em que $i=1,2$. Note que o número de elementos de $\widetilde{\mathbb{T}}_{N}^{[4 \times 2](i)}$, é igual a $N^{2} / 8$.

Desde que o número de sítios em $\widetilde{\mathbb{T}}_{N}$ é igual a $N^{2}$, usando o Lema 5.2.4, obtemos a partir de $(5.31)$

$$
\mathfrak{z}_{\beta, N}\left(\mathcal{B}\left(\sigma_{\Lambda}\right)\right) \leq \exp \left(-\frac{\beta}{4}\left[H_{[2 \times 2]}\left(\sigma_{\Lambda,[2 \times 2]}\right)-H_{[2 \times 2]}\left(\sigma_{\Lambda,[2 \times 2]}^{+}\right)\right]\right),
$$

para todo $\sigma_{\Lambda} \in R(\Lambda)$.

Para provar (5.18), lembramos dos toros $\widetilde{\mathbb{T}}_{N}^{(i)}, i=1,2$, definidos em (3.19) e (3.23), respectivamente. Então, aplicamos a desigualdade

$$
\begin{aligned}
\mathfrak{z}_{\beta, N}^{(i)}\left(\mathcal{B}\left(\sigma_{i}\right)\right)^{\left|\widetilde{\mathbb{T}}_{N}^{(i)}\right|}=\frac{\exp \left(-\beta H_{N}\left(\sigma_{i, N}\right)\right)}{Z_{N}(\beta)} & \leq \exp \left(-\beta\left[H_{N}\left(\sigma_{i, N}\right)-H_{N}\left(\sigma^{+}\right)\right]\right) \\
& =\exp \left(-\frac{\beta}{8} N^{2}\left[H_{[4 \times 2]}\left(\sigma_{i,[4 \times 2]}\right)-H_{[4 \times 2]}\left(\sigma_{i,[4 \times 2]}^{+}\right)\right]\right),
\end{aligned}
$$

ver (5.44). Dado que $\left|\widetilde{T}_{N}^{(i)}\right|=\frac{N^{2}}{2}$, o análogo de (5.48) é

$$
\mathfrak{z}_{\beta, N}^{(i)}\left(\mathcal{B}\left(\sigma_{i}\right)\right) \leq \exp \left(-\frac{\beta}{4}\left[H_{[4 \times 2]}\left(\sigma_{i,[4 \times 2]}\right)-H_{[4 \times 2]}\left(\sigma_{i,[4 \times 2]}^{+}\right)\right]\right)
$$

para $i=1,2$.

Finalmente, a Proposição 5.2.2 decorre do próximo lema. A prova deste lema é essencialmente repetir os argumentos do Lema 3.3 de [36]. Porém, fornecemos a prova para completar a leitura.

Lema 5.2.5. Se h satisfaz (2.8), então para toda configuração $\sigma_{\Lambda} \in R(\Lambda)$, a sua configuração propagada $\sigma_{\Lambda,[2 \times 2]}$, no toro $\mathbb{T}^{[2 \times 2]}$, satisfaz

$$
H_{[2 \times 2]}\left(\sigma_{\Lambda,[2 \times 2]}\right)-H_{[2 \times 2]}\left(\sigma_{\Lambda,[2 \times 2]}^{+}\right) \geq 4\left(2 J-h \frac{L_{1} L_{2}}{L_{1}+L_{2}}\right) .
$$

Além disso, a configuração propagada $\sigma_{i,[4 \times 2]}$, em $\mathbb{T}^{[4 \times 2](i)}$, satisfaz

$$
H_{[4 \times 2]}\left(\sigma_{i,[4 \times 2]}\right)-H_{[4 \times 2]}\left(\sigma_{i,[4 \times 2]}^{+}\right) \geq 4\left(2 J-h \frac{L_{1} L_{2}}{L_{1}+L_{2}}\right), i=1,2 .
$$

Demonstração. A prova é tomada a partir de [36]. Para abreviar as notações, provando (5.51) omitimos os índices $\Lambda,[2 \times 2]$, em todos os lugares para as configurações de $\mathbb{T}^{[2 \times 2]}$. Seja um subconjunto $V \subset \mathbb{T}^{[2 \times 2]}$, a configuração $\sigma^{V}$, é a perturbação de $\sigma$, isto é

$$
\sigma^{V}(t)=\left\{\begin{array}{rr}
-\sigma(t), & \text { se } t \in V, \\
\sigma(t), & \text { se } t \notin V .
\end{array}\right.
$$


Uma configuração $\sigma^{V,+}$, é uma perturbação do estado fundamental $\sigma^{+}$.

Provamos a desigualdade (5.51) para todo $V \neq \emptyset$ e $V \neq \mathbb{T}^{[2 \times 2]}$. Dado $V \subset \mathbb{T}^{[2 \times 2]}$, identificamos arestas $\langle u, v\rangle \subset \mathbb{T}^{[2 \times 2]}$, tal que $u \in V, v \in V^{c}$, então $\sigma^{V,+}(u)=-1$, e $\sigma^{V,+}(v)=+1$. O conjunto dessas arestas compõe o contorno de Peierls (ou simplesmente, um contorno) $\partial V$ de $V$. O contorno de Peierls é a união das arestas horizontais $\partial^{h} V$, e as arestas verticais $\partial^{v} V$, i.e. $\partial V=\partial^{h} V \cup \partial^{v} V$.

Note que,

$$
H_{[2 \times 2]}\left(\sigma^{V,+}\right)-H_{[2 \times 2]}\left(\sigma^{+}\right)=2 J|\partial V|+2 \sum_{s \in V} h(s) .
$$

Agora, representamos $V$ como sendo a união dos conjuntos $\mathcal{S}_{V}=\{S\}$, de linhas horizontais de sítios vizinhos em $V$, ou como união de conjuntos $\mathcal{T}_{V}=\{T\}$, de linhas verticais de sítios conectados. Em seguida

$$
\sum_{s \in V} h(s)=\sum_{S \in \mathcal{S}_{V}} \sum_{s \in S} h(s)=\sum_{T \in \mathcal{T}_{V}} \sum_{s \in T} h(s)
$$

Existem dois tipos de linhas de sítios em $V$ : fechadas ou abertas. No último caso, a linha tem duas extremidades, que pertencem às arestas da fronteira de $\partial V$. Se a linha aberta é horizontal, então existem duas arestas de $\partial^{h} V$, com pontos comuns com dita linha. A mesma propriedade é verdadeira para as linhas abertas verticais que intersectam $\partial^{v} V$. As linhas fechadas não interceptam a fronteira $\partial V$. Estes são círculos fechados em todo o toro $\mathbb{T}^{[2 \times 2]}$.

Seja $\mathcal{S}_{V}=\mathcal{S}_{V}^{c l} \cup \mathcal{S}_{V}^{o p}$, em que $\mathcal{S}_{V}^{c l}$ é o subconjunto das linhas horizontais fechadas, e $\mathcal{S}_{V}^{o p}$ é o subconjunto das linhas horizontais abertas de $V$. A representação semelhante vale para as linhas verticais, $\mathcal{T}_{V}=\mathcal{T}_{V}^{c l} \cup \mathcal{T}_{V}^{o p}$. Observe que dada a estrutura do campo externo no toro, para as linhas fechadas, tanto horizontais quanto verticais, é verdadeiro que

$$
\begin{aligned}
& \sum_{s \in S} h(s)=0 \\
& \sum_{s \in T} h(s)=0
\end{aligned}
$$

em que $S \in \mathcal{S}_{V}^{c l}$, e $T \in \mathcal{T}_{V}^{c l}$.

Para as linhas abertas, obtemos as seguintes estimativas

$$
\begin{aligned}
\left|\sum_{s \in S} h(s)\right| & =h|| S \cap \mathbf{Z}_{+}|-| S \cap \mathbf{Z}_{-} \| \leq h L_{1}, \\
\left|\sum_{s \in T} h(s)\right| & =h|| T \cap \mathbf{Z}_{+}|-| T \cap \mathbf{Z}_{-} \| \leq h L_{2},
\end{aligned}
$$

em que $S \in \mathcal{S}_{V}^{o p}$, e $T \in \mathcal{T}_{V}^{o p}$.

Isto implica as seguintes desigualdades

$$
\begin{aligned}
& 2 \sum_{S \in \mathcal{S}_{V}} \sum_{s \in S} h(s) \geq-2 h L_{1}\left|\mathcal{S}_{V}\right| \geq-h L_{1}\left|\partial^{h} V\right|, \\
& 2 \sum_{T \in \mathcal{T}_{V}} \sum_{s \in T} h(s) \geq-2 h L_{2}\left|\mathcal{T}_{V}\right| \geq-h L_{2}\left|\partial^{v} V\right|
\end{aligned}
$$


Finalmente, por (5.55) e (5.58), temos que

$$
\begin{aligned}
H_{[2 \times 2]}\left(\sigma^{V,+}\right)-H_{[2 \times 2]}\left(\sigma^{+}\right) & =2 J|\partial V|+\frac{L_{1}}{L_{1}+L_{2}}\left(2 \sum_{s \in V} h(s)\right)+\frac{L_{2}}{L_{1}+L_{2}}\left(2 \sum_{s \in V} h(s)\right) \\
& \geq 2 J|\partial V|-h \frac{L_{1} L_{2}}{L_{1}+L_{2}}\left|\partial^{h} V\right|-h \frac{L_{1} L_{2}}{L_{1}+L_{2}}\left|\partial^{v} V\right| \\
& =\left(2 J-h \frac{L_{1} L_{2}}{L_{1}+L_{2}}\right)|\partial V| .
\end{aligned}
$$

Claramente, para cada $V \subset \mathbb{T}^{[2 \times 2]},|\partial V| \geq 4$. Assim, temos provado (5.51).

A prova de (5.52) não difere da anterior.

Pela subaditividade de $\mathfrak{z}_{\beta, N}$ (ver (3.30)), e usando (5.16), temos que

$$
\begin{aligned}
\mathfrak{z}_{\beta, N}(\mathcal{R}) & \leq \sum_{\sigma_{\Lambda} \in R(\Lambda)} \mathfrak{z}_{\beta, N}\left(\mathcal{B}\left(\sigma_{\Lambda}\right)\right) \\
& \leq \sum_{\sigma_{\Lambda} \in R(\Lambda)} \exp \left(-\beta\left(2 J-h \frac{L_{1} L_{2}}{L_{1}+L_{2}}\right)\right) \\
& =|R(\Lambda)| \exp \left(-\beta\left(2 J-h \frac{L_{1} L_{2}}{L_{1}+L_{2}}\right)\right) .
\end{aligned}
$$

O número $|R(\Lambda)|$, de configurações $\Lambda$-ruim, é estimado com $|R(\Lambda)| \leq 2^{B_{1} B_{2}}$. Isto prova (5.17).

A desigualdade (5.19) é obtida da mesma maneira como (5.17) foi provada, usando a estimativa $\left|R\left(\Lambda^{*}\right)\right| \leq 4^{B_{1} B_{2}}$.

\section{Prova da Proposição 5.2.3.}

Denote $\Omega_{s, t}^{*}=\left\{\sigma \in \Omega_{N}: \sigma(s)=+1\right.$ e $\left.\sigma(t)=-1\right\}$. A seguir, iremos estimar superiormente a probabilidade $\mu_{\beta, N}\left(\Omega_{s, t}^{*}\right)$. Então, para cada $\sigma \in \Omega_{N}^{*}$, definimos o conjunto

$$
I^{+}(\sigma)=\left\{u \in \mathbb{T}_{N}: \sigma(u)=+1\right\}
$$

e seja $I^{+}(\sigma, s) \subseteq I^{+}(\sigma)$, o seu máximo componente conectado contendo o sítio $s$. Os sítios $s$ e $t$, são separados por algum contorno de Peierls $\gamma(\sigma)$. Como acima, o contorno de Peierls é o conjunto de arestas $\{\langle u, v\rangle\}$, tal que $\sigma(u) \neq \sigma(v)$.

Definimos um dual para $\gamma(\sigma)$, isto é, o contorno $\gamma^{*}(\sigma)$. Para esta finalidade consideramos o reticulado dual $\mathbb{Z}^{* 2}$, e o grafo dual $\mathbb{G}^{*}=\left(\mathbb{Z}^{* 2}, \mathbb{E}^{*}\right)$. As arestas $\left\langle u^{*}, v^{*}\right\rangle \in \mathbb{E}^{*}$, são ortogonais às arestas de $\mathbb{E}(\operatorname{ver}(3.1))$. O dual de $\gamma(\sigma)$, o contorno $\gamma^{*}(\sigma)=\left\langle u^{*}, v^{*}\right\rangle$, consiste de todas as arestas duais que são ortogonais às arestas de $\gamma(\sigma)$.

Uma descrição mais formal é a seguinte. Uma aresta $\left\langle u^{*}, v^{*}\right\rangle, \operatorname{com} u^{*}=\left(u_{1}^{*}, u_{2}^{*}\right)$ e $v^{*}=\left(v_{1}^{*}, v_{2}^{*}\right)$, 
dual a $\langle u, v\rangle$, com $u=\left(u_{1}, u_{2}\right)$ e $v=\left(v_{1}, v_{2}\right)$, é definida por

$$
\begin{aligned}
& u_{1}^{*}=\frac{u_{1}+v_{1}}{2}\left|u_{1}-v_{1}\right|+\left(u_{1}+\frac{1}{2}\right)\left|u_{2}-v_{2}\right|, \\
& u_{2}^{*}=\frac{u_{2}+v_{2}}{2}\left|u_{2}-v_{2}\right|+\left(u_{2}+\frac{1}{2}\right)\left|u_{1}-v_{1}\right|, \\
& v_{1}^{*}=\frac{u_{1}+v_{1}}{2}\left|u_{1}-v_{1}\right|+\left(v_{1}-\frac{1}{2}\right)\left|u_{2}-v_{2}\right|, \\
& v_{2}^{*}=\frac{u_{2}+v_{2}}{2}\left|u_{2}-v_{2}\right|+\left(v_{2}-\frac{1}{2}\right)\left|u_{1}-v_{1}\right| .
\end{aligned}
$$

Seja $\gamma^{e x t}(\sigma, s) \subseteq \gamma^{*}(\sigma)$ tal que todo ponto $r \in \gamma^{\text {ext }}(\sigma, s)$, pode ser conectado com o sítio $t$ por uma linha em $\widehat{\mathbb{T}}_{N}$ evitando $\widehat{I}^{+}(\sigma, s)$ (veja (3.2)). Seja $\widehat{J}^{+}(\sigma, s) \subset \widehat{\mathbb{T}}_{N}$, contendo o sítio $s$, e cuja fronteira é unicamente $\gamma^{e x t}(\sigma, s)$. É claro que $\widehat{J}^{+}(\sigma, s) \supset \widehat{I}^{+}(\sigma, s)$. O contorno $\gamma^{e x t}(\sigma, s)$, é chamado um contorno externo relativo ao sítio $s$. Ver Figura 5.2, para um exemplo genérico.

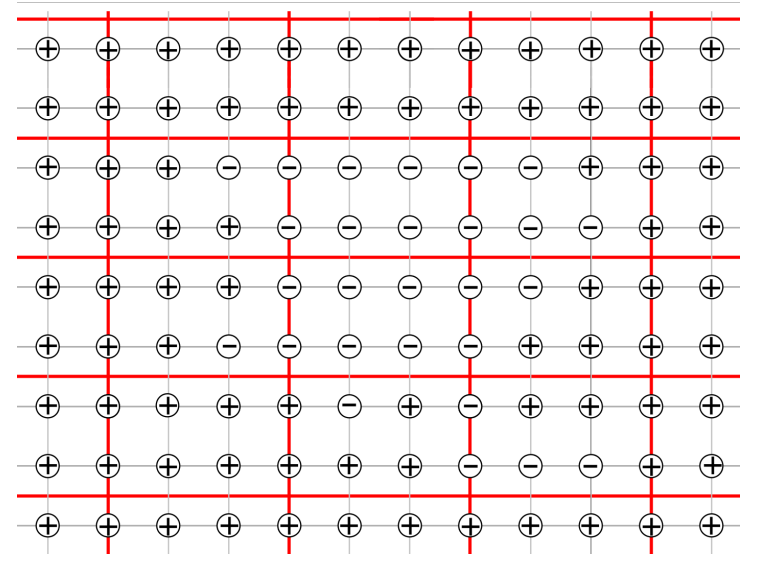

(a)

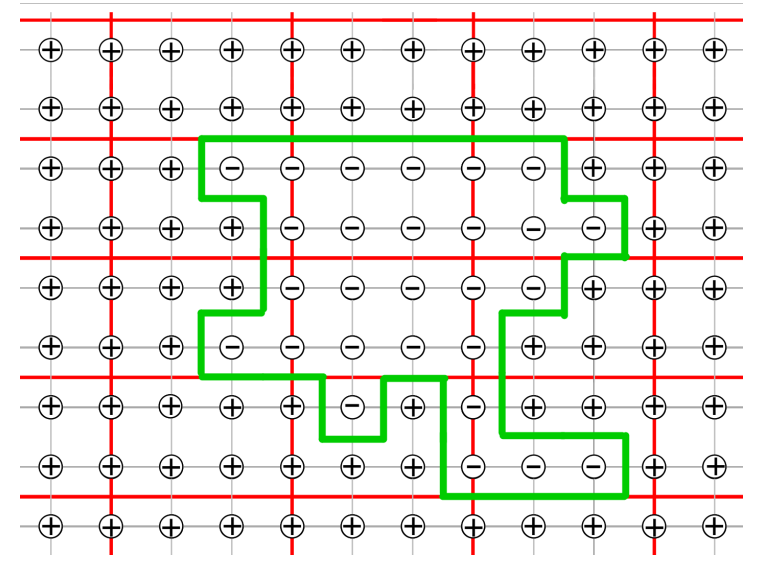

(b)

Figura 5.2: (a) Representação de uma configuração $\sigma \in \Omega^{*}$. (b) A linha verde, formada por arestas do grafo dual, ilustra o correspondente contorno externo $\gamma^{\text {ext }}(\sigma)$.

Denote $\Gamma_{s, t}=\left\{\gamma^{e x t}(\sigma, s): \sigma \in \Omega_{N}^{*}\right\}$, o conjunto de todos os contornos externos.

Daqui em diante, $\Psi$ denota tanto um bloco como um bloco-duplo. Todo $\Psi$, será chamado de $g$-bloco independente se $\Psi$ é um bloco ou um bloco-duplo. Lembre-se que $\Psi$, é um subgrafo de (3.1) embutido em $\mathbb{R}^{2}$. Portanto, $\Psi$ juntamente com as suas arestas que terminam no fecho convexo de $\Psi$, é um subconjunto de $\mathbb{R}^{2}$.

Seja $\Psi$ um bloco-duplo, e denote $\Lambda^{\prime}$ e $\Lambda^{\prime \prime}$ os blocos vizinhos incluídos em $\Psi$. O subconjunto $\Phi \subset \Psi$, é o conjunto das arestas localizadas entre $\Lambda^{\prime}$ e $\Lambda^{\prime \prime}$, e então $\Psi=\Lambda^{\prime} \cup \Phi \cup \Lambda^{\prime \prime}$. O conjunto $\Phi$ será chamada de "faixa". Todo bloco-duplo é unicamente definido por sua faixa. Se $\Psi$, é um bloco-duplo, então denotamos $\Phi_{\Psi}$ a faixa correspondente. Também, denotamos $\Phi_{\Psi}^{*}$, o conjunto das arestas duais a $\Phi_{\Psi}$. Finalmente, para tal bloco-duplo $\Psi$, dizemos que: $\Psi \cap \gamma^{\text {ext }} \neq \emptyset$, se $\Phi_{\Psi}^{*} \subset \gamma^{\text {ext }}$.

Denote $\mathfrak{P}=\{\Psi\}$, o conjunto de todos os blocos e blocos-duplos. Para todo $\sigma \in \Omega_{N}$, defina o conjunto $\Sigma(\sigma)=\{\sigma(\Psi): \Psi \in \mathfrak{P}\}$, das restrições da configuração $\sigma$ sobre todo $\Psi \in \mathfrak{P}$. Se $\sigma \in \Omega_{s, t}^{*}$, vamos definir $\mathcal{E}=\mathcal{E}\left(\gamma^{e x t}\right)=\left\{\Psi: \Psi \cap \gamma^{\text {ext }} \neq \emptyset\right\}$, em que $\gamma^{\text {ext }}=\gamma^{\text {ext }}(\sigma, s)$. Seja $\mathcal{E}_{b} \subseteq \mathcal{E}$, um subconjunto dos blocos-duplos. Os restantes blocos são $\mathcal{E}_{0}=\mathcal{E} \backslash \mathcal{E}_{b}$. Todo bloco provindo de $\mathcal{E}_{0}$ não faz parte de $\mathcal{E}_{b}$. 
O conjunto $\mathcal{E}=\mathcal{E}\left(\gamma^{\text {ext }}\right)$ é chamado contorno exterior de blocos, correspondente ao contorno externo de Peierls, $\gamma^{\text {ext }}$. Denote $\Omega^{*}(\mathcal{E})$, o conjunto das configurações $\sigma$, que geram o contorno exterior de blocos $\mathcal{E}$. Ver Figura 5.3.

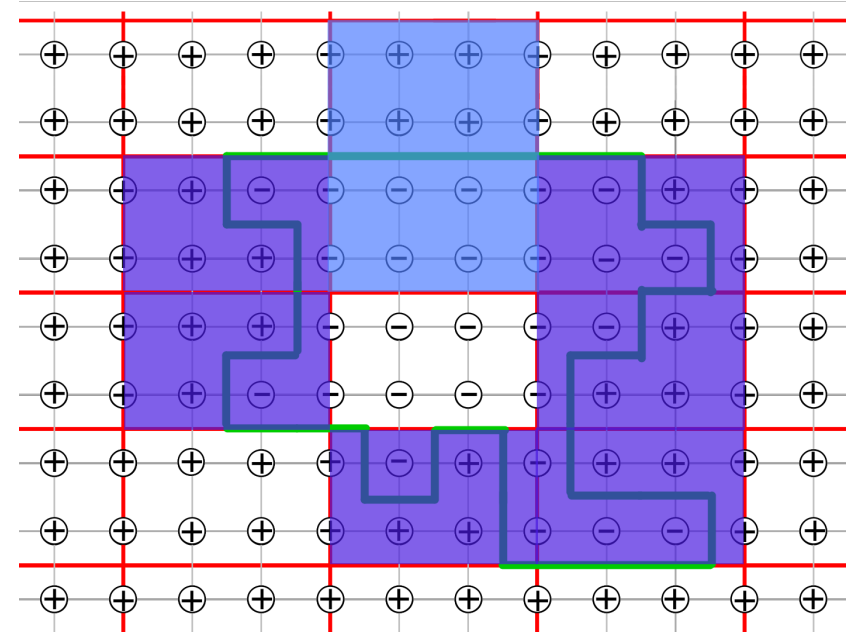

Figura 5.3: $O$ contorno de blocos associado à configuração $\sigma \in \Omega^{*}$ e o contorno externo $\gamma^{\text {ext }}(\sigma)$, definidos na Figura 5.2. Observe que este contorno é composto por seis $\Lambda$-blocos e um bloco-duplo, o qual contém dois $\Lambda$-blocos vizinhos com configurações $\sigma$-boas.

Se $\sigma \in \Omega^{*}(\mathcal{E})$, então $\sigma \in \bigcap_{\Psi \in \mathcal{E}_{0}} \mathcal{B}\left(\sigma_{\Psi}\right) \cap \bigcap_{\Psi^{*} \in \mathcal{E}_{b}} \mathcal{B}\left(\sigma_{\Psi^{*}}\right)$. Além disso, $\sigma \in \bigcap_{\Psi \in \mathcal{E}_{0}} \mathcal{R}_{\Psi} \bigcap_{\Psi^{*} \in \mathcal{E}_{b}} \mathcal{R}_{\Psi^{*}}$. Isto é:

$$
\Omega^{*}(\mathcal{E}) \subset \bigcap_{\Psi \in \mathcal{E}} \mathcal{R}_{\Psi}
$$

Baseados nesta inclusão, nosso foco agora é estimar $\mu_{\beta, N}\left(\Omega_{s, t}^{*}\right)$.

Desta forma, usando (5.62), a desigualdade de Cauchy-Schwarz, e a estimativa de chessboard, respectivamente, obtemos

$$
\begin{aligned}
& \mu_{\beta, N}\left(\Omega^{*}(\mathcal{E})\right) \leq \mu_{\beta, N}\left(\bigcap_{\Psi \in \mathcal{E}} \mathcal{R}_{\Psi}\right) \leq\left[\mu_{\beta, N}\left(\bigcap_{\Psi \in \mathcal{E}_{0}} \mathcal{R}_{\Psi}\right)\right]^{\frac{1}{2}}\left[\mu_{\beta, N}\left(\bigcap_{\Psi^{*} \in \mathcal{E}_{b}} \mathcal{R}_{\Psi^{*}}\right)\right]^{\frac{1}{2}} \leq \\
& \prod_{\Psi \in \mathcal{E}_{0}}\left[\mu_{\beta, N}\left(\bigcap_{\mathbf{t} \in \widetilde{\mathbb{T}}_{N}} \pi_{\mathbf{t}}\left(\mathcal{R}_{\Psi}\right)\right)\right]^{\frac{1}{2 N^{2}}} \prod_{\Psi^{*} \in \mathcal{E}_{b}}\left[\mu_{\beta, N}\left(\bigcap_{\mathbf{t} \in \widetilde{\mathbb{T}}_{N}^{(i)}} \pi_{\mathbf{t}}\left(\mathcal{R}_{\Psi^{*}}\right)\right)\right]^{\frac{1}{2\left(N^{2} / 2\right)}}
\end{aligned}
$$

Lembre que, $N^{2}$ é o número de blocos simples, e $N^{2} / 2$ é o número de blocos-duplos. O número de blocos é igual ao número de elementos em $\widetilde{\mathbb{T}}_{N}$, e o número de blocos-duplos é igual ao número de elementos em $\widetilde{\mathbb{T}}_{N}^{(i)}$, com $i=1$ ou $i=2$. As probabilidades $\mu_{\beta, N}\left(\bigcap_{\mathbf{t} \in \widetilde{\mathbb{T}}_{N}} \pi_{\mathbf{t}}\left(\mathcal{R}_{\Psi}\right)\right)$, quando $\Psi \in \mathcal{E}_{0}$, e $\mu_{\beta, N}\left(\bigcap_{\mathbf{t} \in \widetilde{\mathbb{T}}_{N}^{(i)}} \pi_{\mathbf{t}}\left(\mathcal{R}_{\Psi^{*}}\right)\right)$, quando $\Psi^{*} \in \mathcal{E}_{b}$, não dependem da posição de $\Psi$ (ou de $\Psi^{*}$ ). Então, definimos a quantidade $\mu_{\beta, N}\left(\bigcap_{\mathbf{t} \in \widetilde{\mathbb{T}}_{N}} \pi_{\mathbf{t}}(\mathcal{R})\right)$, ou seja, a probabilidade de algum bloco-ruim propagado. Também, definimos a magnitude $\mu_{\beta, N}\left(\bigcap_{\mathbf{t} \in \widetilde{T}_{N}^{(i)}} \pi_{\mathbf{t}}\left(\mathcal{R}^{*}\right)\right)$, isto é, a probabilidade de algum bloco-duplo-ruim propagado, ou seja, a propagação do evento $\mathcal{R}^{*}$. Desde (5.63), obtemos 


$$
\mu_{\beta, N}\left(\Omega^{*}(\mathcal{E})\right) \leq\left[\mu_{\beta, N}\left(\bigcap_{\mathbf{t} \in \widetilde{\mathbb{T}}_{N}} \pi_{\mathbf{t}}(\mathcal{R})\right)\right]^{\frac{\left|\mathcal{E}_{0}\right|}{2 N^{2}}}\left[\mu_{\beta, N}\left(\bigcap_{\mathbf{t} \in \widetilde{\mathbb{T}}_{N}^{(i)}} \pi_{\mathbf{t}}\left(\mathcal{R}^{*}\right)\right)\right]^{\frac{\left|\mathcal{E}_{b}\right|}{2\left(N^{2} / 2\right)}} .
$$

Usando as notações de (3.28) e (3.29), e aplicando as desigualdades (5.17) e (5.19), então

$$
\mu_{\beta, N}\left(\Omega^{*}(\mathcal{E})\right) \leq \mathfrak{z}_{\beta, N}(\mathcal{R})^{\frac{\left|\mathcal{E}_{0}\right|}{2}} \mathfrak{z}_{\beta, N}\left(\mathcal{R}^{*}\right)^{\frac{\left|\mathcal{E}_{b}\right|}{2}} \leq 2^{B_{1} B_{2} \frac{\left|\mathcal{E}_{0}\right|}{2}} 4^{B_{1} B_{2} \frac{\left|\mathcal{E}_{b}\right|}{2}} \exp \left\{-\frac{\beta}{2}|\mathcal{E}|\left(2 J-\frac{h L_{1} L_{2}}{L_{1}+L_{2}}\right)\right\} .
$$

O seguinte passo é definir $\mathfrak{D}_{s, t}=\left\{\mathcal{E}=\mathcal{E}\left(\gamma^{E x t}\right), \gamma^{E x t} \in \Gamma_{s, t}\right\}$. Em seguida, estimamos $\mu_{\beta, N}\left(\Omega_{s, t}^{*}\right)$, a partir da inclusão $\Omega_{s, t}^{*} \subset \bigcup_{\mathcal{E} \in \mathfrak{D}_{s, t}} \Omega^{*}(\mathcal{E})$. Usando a desigualdade (5.64), e um argumento combinatório, obtemos

$$
\begin{aligned}
& \mu_{\beta, N}\left(\Omega_{s, t}^{*}\right) \leq \sum_{\mathcal{E} \in \mathfrak{D}_{s, t}} \mu_{\beta, N}\left(\Omega^{*}(\mathcal{E})\right) \leq \sum_{n} \sum_{\substack{n_{0}, n_{b}: \\
n_{0}+n_{b}=n}} c^{n_{0}} 2^{n_{0} B_{1} B_{2} / 2} c^{2 n_{b}} 4^{n_{b} B_{1} B_{2} / 2} \exp \left\{-\frac{\beta}{2} n \alpha\right\}= \\
& \sum_{n} c^{n} 2^{n B_{1} B_{2} / 2}\left(c 2^{B_{1} B_{2} / 2}+1\right)^{n} \exp \left\{-\frac{\beta}{2} n \alpha\right\} \leq \sum_{n}\left[c(c+1) 2^{B_{1} B_{2}} \exp \{-\beta \alpha / 2\}\right]^{n},
\end{aligned}
$$

em que $\alpha=2 J-\frac{h L_{1} L_{2}}{L_{1}+L_{2}}, n_{0}=\left|\mathcal{E}_{0}\right|, n_{b}=\left|\mathcal{E}_{b}\right|$, e $c$ é uma constante combinatória relacionada com o número de contornos de blocos. A forma como a constante $c$ aparece em (5.65), é definida como o número de contornos de blocos tendo seu comprimento igual a $n$ (ver abaixo uma justificação).

Finalmente, se

$$
\beta>\frac{2\left[\left(B_{1} B_{2}+1\right) \ln (2)+\ln (c(c+1))\right]}{2 J-\frac{h L_{1} L_{2}}{L_{1}+L_{2}}},
$$

então,

$$
\mu_{\beta, N}\left(\Omega_{s, t}^{*}\right) \leq 2 c(c+1) 2^{B_{1} B_{2}} \exp \left\{-\frac{\beta}{2}\left(2 J-\frac{h L_{1} L_{2}}{L_{1}+L_{2}}\right)\right\} .
$$

\section{Estimação da constante combinatória.}

Em seguida, calculamos a constante $c$, e damos uma justificativa para a equação (5.65)

Lema 5.2.6. $c=9$.

Demonstração. Calculando o número de contornos de blocos, com o comprimento igual a n, construímos o grafo relacionado a tal contorno. Suponha que $N \geq 5 n$. O contorno de blocos, separando $s$ e $t$, significa que, ou $\Lambda_{s}$ (o bloco que contém o sítio $s$ ) é cercad pelo contorno, ou $\Lambda_{s}$ pertence ao contorno. A seguir, estimamos o número de grafos ao invés do número de contornos.

Precisamos da seguinte notação, seja $\mathcal{G}_{\mathcal{E}}^{0}$ o conjunto de todos os blocos que constituem $\mathcal{E}$. Se $\Psi^{*}=\left\{\Psi^{\prime}, \Psi^{\prime \prime}\right\} \in \mathcal{E}$, é um bloco-duplo de $\mathcal{E}$, então $\Psi^{\prime}$ e $\Psi^{\prime \prime} \in \mathcal{G}_{\mathcal{E}}^{0}$. Os pontos centrais do casco 
convexo de $\Psi \in \mathcal{G}_{\mathcal{E}}^{0}$, pertencem a $\mathbb{R}^{2}$, e serão os vértices do grafo. Arestas do grafo conectam os blocos vizinhos de $\mathcal{G}_{\mathcal{E}}^{0}$. O número de grafos é um limitante superior do número dos contornos de blocos.

O número de vizinhos de qualquer vértice é não superior a 4.

O método padrão para avaliar o número dos grafos, é lançar um caminho ao longo das arestas do grafo. No caso de duas dimensões, cada passo do caminho dá 3 possibilidades. Portanto, o limite superior do número dos caminhos é $3^{n}$. No caso dos contornos de blocos, é preciso passar duas vezes através do grafo. Isto entrega o limitante superior $9^{n}$.

Justificação de (5.65). Os blocos-duplos criam dois vértices vizinhos no grafo. Portanto, o bloco-duplo está sendo levado em conta duas vezes em (5.65). Assim, a contribuição da energia de um bloco-duplo, é estimada em $c^{2 n_{b}} 4^{n_{b} B_{1} B_{2}} \exp \left\{-\beta \alpha n_{b}\right\}$. Esta é uma justificativa de (5.65), que diz respeito à energia dos blocos-duplos

Finalmente, o limitante (4.3) segue a partir (5.29), isto é

$$
\beta_{c} \leq \frac{2\left[\left(B_{1} B_{2}+4\right) \ln (2)+\ln (90)\right]}{2 J-\frac{h L_{1} L_{2}}{L_{1}+L_{2}}} .
$$

\subsection{Prova da transição de fase no modelo de Ising com faixas alter- nadas}

Para provar a transição de fase para este modelo, seguimos o roteiro da prova do Teorema 4.2.1. Em geral, nesta seção, usaremos a mesma notação do Capítulo 3, sem distinção com o modelo anterior.

Demonstração. Em primeiro lugar, vamos construir um toro $\mathbb{T}_{N}$, considerando um subconjunto $T_{N}$ de $\mathbb{Z}^{2}$, de tamanho $N \times N L$ sítios:

$$
T_{N}=\left\{t=\left(t_{1}, t_{2}\right) \in \mathbb{Z}^{2}: 0 \leq t_{1}<N, 0 \leq t_{2}<N L\right\}
$$

onde $N$ é par. Impomos condições de contorno periódicas. Em outra palavras, $\mathbb{T}_{N}$ é o grupo quociente: $\mathbb{Z} /(N \mathbb{Z}) \times \mathbb{Z} /(N L \mathbb{Z})$.

De forma análoga a (3.10), definimos o conjunto de planos $\mathcal{P}=\mathcal{P}_{1} \cup \mathcal{P}_{2}$, dado por

$$
\begin{gathered}
P_{1}^{(n)}=\left\{t=\left(t_{1}, t_{2}\right) \in \mathbb{R}^{2}: t_{1}=n\right\}, \\
P_{2}^{(n)}=\left\{t=\left(t_{1}, t_{2}\right) \in \mathbb{R}^{2}: t_{2}=n L+(L-1) / 2\right\},
\end{gathered}
$$

em que $n$ é um inteiro positivo menor que $N$, e $\mathcal{P}_{1}=\left\{P_{1}^{(n)}\right\}$, e $\mathcal{P}_{2}=\left\{P_{2}^{(n)}\right\}$. 
O conjunto de linhas $\mathcal{P}$, decompõe o toro $\mathbb{T}_{N}$ em blocos retangulares (veja a Figura 5.4). Observe que dentro de cada bloco, a soma do campo externo é igual a zero.

Para continuar, e de maneira simples, verificamos que (5.30) é válida para todos os planos $P \in \mathcal{P}$. Basta utilizar as mesmas funções usadas na prova da Proposição 5.2.1.

Uma vez que a propriedade de RP está garantida, aplicamos as estimativas de chessboard (ver (3.26) e (3.27)). Para este motivo, definimos os $\Lambda$-blocos por translações do bloco $\Lambda$. Construímos $\Lambda$, considerando em $\mathbb{R}^{2}$ o retângulo

$$
\tilde{\Lambda}=\left\{\left(t_{1}, t_{2}\right):\left|t_{1}+\frac{1}{2}\right| \leq \frac{1}{2},\left|t_{2}+\frac{1}{2}\right| \leq \frac{L}{2}\right\} .
$$

Então, $\Lambda=\tilde{\Lambda} \cap \mathbb{Z}^{2}$. De outra forma, $\widetilde{\mathbb{T}}_{N}=\left\{\mathbf{t}=\left(t_{1}, t_{2}\right) \in \mathbb{T}_{N}: t_{1}=n, t_{2}=m L, n, m \in \mathbb{Z}\right\}$.

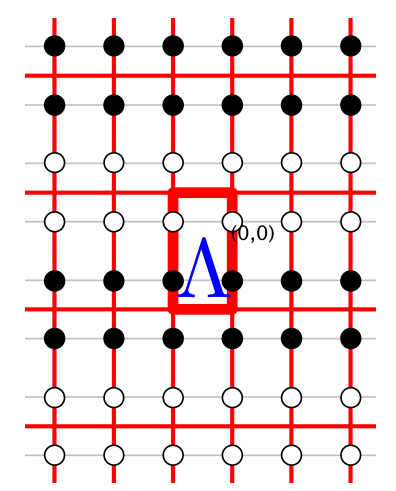

Figura 5.4: $O$ modelo estudado na Seção 4.2.3 com $L=2$. Este modelo pode ser considerado como um modelo do tipo cell-board com $L_{1}=\infty$, e $L_{2}=2$.

Esta construção particular do toro $\widetilde{\mathbb{T}}_{N}$, permite-nos provar a transição de fase. A seguir, usamos a definição do "evento bloco-ruim" (ver (5.10) para a definição de $R(\Lambda)$, e (5.11) para o evento $\mathcal{R}$ ).

De forma análoga à prova da Proposição 5.2.2, se $h<2 J / L$, podemos provar que para toda configuração $\Lambda$-ruim, $\sigma_{\Lambda} \in R(\Lambda)$, a desigualdade

$$
\mathfrak{z}_{\beta, N}\left(\mathcal{B}\left(\sigma_{\Lambda}\right)\right) \leq \exp \{-\beta(2 J-h L)\},
$$

vale para todo $N$ par. Além disso, para cada configuração $\sigma_{\Lambda^{*}} \in R\left(\Lambda^{*}\right)$, a desigualdade similar

$$
\mathfrak{z}_{\beta, N}^{(2)}\left(\mathcal{B}\left(\sigma_{\Lambda^{*}}\right)\right) \leq \exp \{-\beta(2 J-h L)\},
$$

vale para todo $N$ múltiplo de 4 .

Note que o o Lema 5.2.4, ainda vale para este modelo. Porém, o Lema 5.2.5 deve ser re-escrito. Portanto, iremos explicar os passos a seguir, para obter a desigualdade (5.70).

Desta forma, seguimos (5.54) para estimar

$$
H_{[2 \times 2]}\left(\sigma^{V,+}\right)-H_{[2 \times 2]}\left(\sigma^{+}\right) .
$$

Lembre que $V \subset \mathbb{T}_{N}$, representa um cluster de sítios com spins iguais a -1 . Agora, usamos a 
decomposição em linhas verticais $\mathcal{T}_{V}=\{T\}$, ou seja, $V=\bigcup_{T \in \mathcal{T}_{V}} T$.

Da desigualdade (5.57), consideramos

$$
\left|\sum_{s \in T} h(s)\right| \leq h L
$$

para cada $T \in \mathcal{T}_{V}$.

Isto implica, como em (5.58) que

$$
2 \sum_{s \in V} h(s)=2 \sum_{T \in \mathcal{T}_{V}} \sum_{s \in T} h(s) \geq-h L\left|\partial^{v} V\right| .
$$

Lembre que, $|\partial V|=\left|\partial^{h} V\right|+\left|\partial^{v} V\right| \geq 4$. Finalmente, temos que

$$
\begin{aligned}
H_{[2 \times 2]}\left(\sigma^{V,+}\right)-H_{[2 \times 2]}\left(\sigma^{+}\right) & \geq 2 J|\partial V|-h L\left|\partial^{v} V\right| \\
& \geq 4(2 J-h L) .
\end{aligned}
$$

Lembre que para provar (5.71), as considerações são similares.

Por outra parte, da mesma forma que (5.60), dizemos que

$$
\mathfrak{z}_{\beta, N}(\mathcal{R}) \leq|R(\Lambda)| \exp (-\beta(2 J-h L)) .
$$

O número de configurações $\Lambda$-ruim, é estimado com $|R(\Lambda)| \leq 2^{2 L^{\prime}}$. Neste caso, $L^{\prime}=L$, quando $L$ é par, e $L^{\prime}=L+1$, se $L$ é ímpar.

Portanto, agora podemos enunciar um resultado similar à Proposição 5.2.3. Isto é, para todo $s, t \in \mathbb{T}_{N}$, a seguinte desigualdade

$$
\mu_{\beta, N}(\sigma(s)=+1, \sigma(t)=-1) \leq 2 c(c+1) 2^{2 L^{\prime}} \exp \left\{-\frac{\beta}{2}(2 J-h L)\right\},
$$

vale para todo $\beta>k /(2 J-h L)$. Aqui, a constante $c$, é a mesma e será estimada por $c=9$, ver Lema 5.2.6.

Como último passo, repetimos considerações com as medidas condicionais

$$
\mu_{\beta, N}^{ \pm}(\cdot):=\mu_{\beta, N}(\cdot \mid \sigma(t)= \pm 1)
$$

em que $t \in \mathbb{T}_{N}$, tal que $t=s+(N / 2,0)$. Também, podemos dizer que

$$
\mu_{\beta, N}(\sigma: \sigma(\Lambda) \equiv+1)=\mu_{\beta, N}(\sigma: \sigma(\Lambda) \equiv-1) \geq \frac{1-\mathfrak{z}_{\beta, N}(\mathcal{R})}{2} .
$$

Para conferir a igualdade acima, considere alguma configuração $\sigma \in \Omega_{N}$, tal que $\sigma(\Lambda) \equiv+1$. Assim, podemos construímos $\sigma^{\prime}=-\theta_{Q_{2}}(\sigma) \in \Omega_{N}$, (ver equação (3.15)). Então, $H_{N}(\sigma)=H_{N}\left(\sigma^{\prime}\right)$.

Finalmente, quando $N \rightarrow \infty$, obtemos as medidas de Gibss a volume-infinito, $\mu_{\beta}^{+}$e $\mu_{\beta}^{-}$. Então, por (5.76) e (5.77), existe uma constante $k>0$, tal que para todo $\beta>k /(2 J-h L)$, 


$$
\mu_{\beta}^{+}(\sigma(s)=-1)<\frac{1}{2} \text { e } \quad \mu_{\beta}^{-}(\sigma(s)=+1)<\frac{1}{2} .
$$




\section{Referências Bibliográficas}

[1] Aizenman, M. Geometric analysis of $\varphi^{4}$ fields and Ising models. Parts I and II. Commun. Math. Phys. 86: 1-48 (1982). 14

[2] Aizenman, M., Fernández, R. On the critical behavior of the magnetization in high-dimensional Ising models. J. Stat. Phys. 44: 393-454 (1986). 14

[3] Aizenman, M., Wehr, J. Rounding of First-Order Phase Transitions in Systems with Quenched Disorder. Phys. Rev. Lett., 62, 2503 (1989). Erratum: PRL, 64, 1311 (E) (1990). 2

[4] Aizenman, M., Wehr, J. Rounding effects of quenched randomness on first-order phase transitions. Commun. Math. Phys., 130(3): 489-528 (1990). 2

[5] van den Berg, J. A Uniqueness Condition for Gibbs Measures, with Application to the 2Dimensional Ising Antiferromagnet. Commun. Math. Phys. 152: 161-166 (1993). 3, 9, 11, 13, $22,23,24$

[6] van den Berg, J., Maes, C. Disagreement percolation in the study of Markov fields. Ann. Probab. 22: 749-763 (1994). 3, 11, 22, 23, 24

[7] Biskup, M. Reflection Positivity and Phase Transitions in Lattice Spin Models in: Methods of Contemporary Mathematical Statistical Physics, ed. Roman Kotecký. Springer-Verlag, Berlin, 2009. 1, 8, 13, 14, 21, 22, 37

[8] Biskup, M., Kotecký, R. Forbidden gap argument for phase transitions proved by means of chessboard estimates. Commun. Math. Phys. 264(3): 631-656 (2006). 2, 13, 15, 16, 21

[9] Bissacot, R., Cioletti, L. Phase Transition in Ferromagnetic Ising Models with Non-uniform External Magnetic Fields. J. Stat. Phys. 139: 769-778 (2010). 2, 11

[10] Bissacot, R., Cassandro, M., Cioletti, L., Presutti, E. Phase Transitions in Ferromagnetic Ising Models with spatially dependent magnetic fields. Commun. Math. Phys. 337: 41-53 (2015). 2, 11

[11] Darbon, J., Sigelle, M. Image Restoration with Discrete Constrained Total Variation Part I: Fast and Exact Optimization. J Math Imaging Vis 26: 261-276 (2006). 1 
[12] Dinaburg, E., Pechersky, E.A., Pirogov, S.A., Shlosman, S.B. and Suhov, Yu.M. From the seminar on Mathematical Statistical Physics in Moscow State University, 1962-1994. Contour Technique. Eur. Phys. J. H 37: 619-637 (2012). 1

[13] Dobrushin, R.L. Existence of a phase transition in the two and three dimensional Ising models. Teor. Ver. Prim. 10(2): 209-230 (1965). Translated in: Theory Probab. Appl. 10: 193-213 (1965). 1

[14] Dobrushin, R.L. The problem of uniqueness of a Gibbs random fields and the problem of phase transition. Funct. Anal. Appl. 2: 302-312 (1968). 9, 26

[15] Dobrushin, R.L., Kolafa, J., Shlosman, S.B. Phase Diagram of the Two-Dimensional Ising Antiferromagnet (Computer-Assisted Proof). Commun. Math. Phys. 102: 89-103 (1985). 5, $9,26,27$

[16] Dobrushin, R.L., Shlosman, S.B. Phases corresponding to the local minima of the energy. Selecta Math. Soviet. 1(4): 317-338 (1981). 13

[17] Dyson, F.J., Lieb, E.H., Simon, B. Phase transitions in quantum spin systems with isotropic and nonisotropic interactions. J. Stat. Phys. 18: 335-383 (1978). 13

[18] Fernández, R., Procacci, A. Cluster expansion for abstract polymer models. New bounds from an old approach. Commun. Math. Phys. 274: 123-140 (2007). 11

[19] Frohlich, J., Israel, R., Lieb, E., Simon, B. Phase transitions and reflection positivity I. Commun. Math. Phys. 62: 1-34 (1978). 13

[20] Frohlich, J., Israel, R., Lieb, E., Simon, B. Phase transitions and reflection positivity II. J. Stat. Phys. 22: 297-347 (1980). 13

[21] Frohlich, J., Lieb, E. Phase transitions in anisotropic lattice spin systems. Commun. Math. Phys. 60: 233-267 (1978). 13

[22] Frohlich, J., Simon, B., Spencer, T. Infrared bounds, phase transitions and continuous symmetry breaking. Commun. Math. Phys. 50: 79-95 (1976). 13

[23] Georgii, H.-O. Gibbs Measures and Phase Transitions. de Gruyter Studies in Mathematics, vol. 9. Walter de Gruyter \& Co., Berlin, 2011. 13

[24] Glimm, J., Jaffe, A., Spencer, T. Phase transition for $\phi_{2}^{4}$ quantum fields. Commun. Math. Phys. 45: 203-216 (1975). 13

[25] González Navarrete, M., Pechersky, E., Yambartsev, A. Phase transition in ferromagnetic Ising model with a cell-board external field. arXiv:1411.7739. 5

[26] Griffiths, R. Peierls proof of spontaneous magnetization of a two-dimensional Ising ferromagnet. Phys.Rev. 136(2A): 437-439 (1964). 1 
[27] Grimmett, G. Percolation. Springer, New York, 1989. 23

[28] Higuchi, Y. Coexistence of the infinite (*) clusters: a remark on the square lattice site percolation. Z. Wahrsch. Verw. Gebiete 6: 175-81 (1982). 23

[29] Ising, E. Beitrag zur Theorie des Ferromagnetismus. Z. Physik 31: 253-258 (1925). 1

[30] Jiménez, A., Tiampo, K.F., Posadas, A.M. An Ising model for earthquake dynamics. Nonlin. Processes Geophys. 14: 5-15 (2007). 1

[31] Kesten, H. Percolation theory for mathematicians. Birkhauser, Boston, 1982. 23

[32] Kotecký, R., Preiss, D. Cluster expansion for abstract polymer models. Commun. Math. Phys. 103: 491-498 (1986). 11

[33] Kotecký, R., Shlosman, S.B. First-order phase transitions in large entropy lattice models. Commun. Math. Phys. 83(4): 493-515 (1982). 13

[34] Lebowitz, J.L., Mazel, A.E. On the uniqueness of Gibbs states in the Pirogov-Sinai theory. Commun. Math. Phys. 189: 311-321 (1997). 11

[35] Lindvall, T. Lectures on the Coupling Method. Wiley, New York, 1992. 23

[36] Maruani, A., Pechersky, E., Sigelle, M. On Gibbs fields in image processing. Markov Processes Relat. Fields, 1: 419-442 (1995). 2, 3, 5, 6, 7, 29, 31, 33, 41

[37] Nardi, F.R., Olivieri, E., Zahradník, M.: On the Ising model with strongly anisotropic external field. J. Stat. Phys., 97: 87-144 (1999). vii, ix, 2, 5, 9, 10, 11, 25, 26, 28, 29

[38] Olivieri, E., Vares, M.E. Large Deviations and Metastability. Cambridge University Press, New York, 2005. 10

[39] Peierls, R. Ising's model of ferromagnetism. Proc. Cambridge Phil. Soc. 32(3): 477-481 (1936). 1

[40] Pirogov, S.A., Sinai, Ya.G. Phase Diagrams of Classical Lattice Systems. Theor. and Math. Phys. 25: 1185-1192 (1975). 2

[41] Pirogov, S.A., Sinai, Ya.G. Phase Diagrams of Classical Lattice Systems. Continuation. Theor. and Math. Phys. 26: 39-49 (1976). 2

[42] Rassoul-Agha, F., Seppäläinen, T. A Course on Large Deviations with an Introduction to Gibbs Measures. Graduate Studies in Mathematics, American Mathematical Society, 2015. 10

[43] Schaap, H. G. Ising models and neural networks. PhD thesis, University of Groningen, 2005. 1

[44] Schneidman, E., Berry, M.J.II, Segev, R., Bialek, W. Weak pairwise correlations imply strongly correlated network states in a neural population. Nature 440: 1007-1012 (2006). 1 
[45] Shlosman, S.B. The method of reflection positivity in the mathematical theory of first-order phase transitions. Russian Math. Surveys 41(3): 83-134 (1986). 2, 13, 21, 37

[46] Sigelle, M. Champs de Markov en traitement d'images et modèles de la physique statistique: application à la relaxation d'images de classification. PhD thesis, ENST, 1993. 1, 2, 5

[47] Sinai, Ya.G. Theory of phase transitions, rigorous results. Pergamon Press - Akademiai Kiado, Budapest, 1972. 1

[48] Toussaint, R., Pride, S. R. Interacting damage models mapped onto Ising and percolation models. Phys. Rev. E 71, 046127 (2005). 1

[49] Zahradník, M. An alternate version of Pirogov-Sinai theory. Commun. Math. Phys. 93: 559-581 (1984). 2, 11

[50] Zahradník, M. A short course on the Pirogov-Sinai theory. Rendiconti di Matematica 18: 1-75 (1998). 2, 11 